\title{
Forme et signification des décors en stuc des sarcophages bosporans
}

\section{Ol'ga Jur'evna Samar}

Traducteur : Laurent Auberson

\section{(2) OpenEdition Journals}

\section{Édition électronique}

URL : https://journals.openedition.org/edl/1695

DOI : $10.4000 /$ edl. 1695

ISSN : 2296-5084

\section{Éditeur}

Université de Lausanne

\section{Édition imprimée}

Date de publication : 15 mai 2019

Pagination : 93-144

ISBN : 978-2-940331-70-3

ISSN : 0014-2026

\section{Référence électronique}

Ol'ga Jur'evna Samar, «Forme et signification des décors en stuc des sarcophages bosporans », Études de lettres [En ligne], 309 | 2019, mis en ligne le 15 mai 2021, consulté le 17 mai 2021. URL http://journals.openedition.org/edl/1695; DOI : https://doi.org/10.4000/edl.1695 


\section{FORME ET SIGNIFICATION DES DÉCORS EN STUC DES SARCOPHAGES BOSPORANS}

La présente contribution étudie les reliefs de stuc qui entrent dans la composition du décor des sarcophages de bois dans le royaume du Bosphore aux I ${ }^{\text {er }}$ et II ${ }^{\mathrm{e}}$ s. apr. J.-C. Ces monuments sont devenus une tradition locale interprétant à sa manière les particularités des rites funéraires grecs et romains, l'iconographie et le style de l'art antique. Ils posent aux chercheurs un certain nombre de questions quant à leur datation, leur attribution, la reconstitution des sarcophages et de leur décor, et soulèvent aussi celle de l'évolution de l'art bosporan dans son ensemble et de l'influence des composantes provenant du monde grec, de l'Asie Mineure, du monde romain et du monde barbare.

\section{Introduction}

La décoration des parois de sarcophages par des sculptures et des reliefs en stuc représente une variante particulière, bosporane, d'une tradition courante dans l'Antiquité et connue par les sarcophages de marbre à reliefs d'Attique, d'Asie Mineure et de Rome. Les reliefs montrent une diversité de figures et de motifs ornementaux. Ils étaient peints en couleur. D’après les découvertes archéologiques, il semble qu'il était d'usage de recouvrir le sarcophage d'une peinture blanche sur laquelle les diverses couleurs des ornements faisaient un effet particulièrement lumineux ${ }^{1}$.

Aux $\mathrm{I}^{\mathrm{er}}$ et $\mathrm{II}^{\mathrm{e}}$ s. apr. J.-C., le passage de la pratique de l'incinération à celle de l'inhumation favorisa le développement des sarcophages. Vers le début du II siècle, les caveaux familiaux devinrent particulièrement

I. N. K. Žižina, «Kompleks gipsovykh rel'efov iz zemljanogo sklepa nekropolja Nimfeja i voprosy rekonstukcii dekora bosporskikh derevjannykh sarkofagov rimskogo vremeni», p. 156 sq. 
répandus dans les nécropoles romaines. La décoration intérieure reproduisait l'aménagement de la maison. On trouve dans la tradition bosporane un reflet de ces deux tendances: d'une part les caveaux peints et de l'autre les sarcophages décorés.

Il est important de faire observer que cette époque fut celle d'un second essor pour le royaume du Bosphore, et l'émergence d'une tradition artistique régionale souligne cette renaissance de l'État. En outre, le règne d'Aspourgos marqua le début de la barbarisation de la classe dirigeante, phénomène qui a donné des traits caractéristiques au style régional.

Durant une centaine d'années, du milieu du $\mathrm{I}^{\mathrm{er}}$ au milieu du $\mathrm{II}^{\mathrm{e}}$ s. apr. J.-C. ${ }^{2}$, les stucs ornant les sarcophages de bois furent très en vogue dans les milieux aisés du royaume du Bosphore. Les reliefs en stuc semblent avoir été ensuite supplantés par la sculpture sur bois et la peinture ${ }^{3}$.

Réalisés durant une période relativement courte et n'ayant pas connu une large diffusion, les décors en stuc devinrent une tradition spécifiquement bosporane ${ }^{4}$. Les principales collections se trouvent au Musée et Parc d'histoire culturelle de la Crimée orientale à Kertch ${ }^{5}$, au Musée de l'Ermitage à Saint-Pétersbourg, au Musée des beaux-arts Pouchkine à Moscou ${ }^{6}$, au Musée national d'histoire à Moscou, au Musée-réserve archéologique de Taman, au Musée d'art occidental et oriental de Kiev et au Musée archéologique d'Odessa. Cette catégorie d'objets est également représentée au Musée du Louvre à Paris ${ }^{7}$, au British Museum à Londres, à l'Ashmolean Museum à Oxford et dans d'autres musées encore.

Le principal problème auquel se heurte la recherche sur les reliefs en stuc est, dans la majorité des cas, l'absence de documentation sur les circonstances de découverte et la nature du contexte archéologique. La

2. N. K. Žižina, "Gipsovye tragičeskie maski kak èlement dekora bosporskikh derevjannykh sarkofagov I-II vekov", p. 90.

3. N. K. Žižina, Gipsovyj rel'efv pogrebal'nykh pamjatnikakh Evropejskogo Bospora pervykh vekov n. è., p. 99.

4. Encore que l'on connaisse aussi des sarcophages hellénistiques à reliefs en terre cuite et des appliques en stuc de l'époque des Ptolémées. Cf. P. Pinelli, A. Wąsowicz, Catalogue des bois et stucs grecs et romains provenant de Kertch, p. 26.

5. Mirovoe nasledie Evropejskogo Bospora, $\mathrm{n}^{\text {os } 207-222 .}$

6. L. I. Akimova, O. V. Tuguščeva (otv. red.), Šedevry antičnogo iskusstva, p. 416419, no 150, fig. 50.

7. P. Pinelli, A. Wąsowicz, Catalogue des bois et stucs grecs et romains provenant de Kertch; N. K. Žižina, «Izdelija iz dereva i gipsovye ukrašenija derevjannykh sarkofagov iz Pantikapeja v sobranii Luvra». 
reconstitution des principes qui régissent les décors et, corrélativement, de la symbolique des sarcophages en est rendue d'autant plus difficile. Les conditions sont très différentes pour les objets provenant de fouilles archéologiques effectuées sur les sites de Nymphée dans les années 1960-1970 (conservés au Musée de l'Ermitage), de Tyritakè en 19331934 (Musée des Beaux-Arts Pouchkine), de Néapolis des Scythes ${ }^{8}$, de la nécropole d'Artezian ${ }^{9}$ et de la nécropole de Phanagorie ${ }^{10}$, qui fournissent une base pour la datation des ensembles de stucs et permettent d'émettre des hypothèses de reconstitution de quelques sarcophages en bois à appliques de stuc.

\section{Histoire de la recherche}

De nombreux auteurs antiques évoquent déjà les sculptures en plâtre: Théophraste, Pline l'Ancien, Pausanias, Juvénal ${ }^{11}$. Leurs écrits attestent l'usage courant de ces objets à l'époque romaine. Des petits bustes en stuc sont également connus à Panticapée au II' s. apr. J.-C. ${ }^{12}$.

Dans la recherche moderne, ce sont les fouilles des grandes nécropoles bosporanes de Panticapée et Phanagorie, ainsi que des petites cités de Nymphée et Tyritakè qui ouvrirent à la connaissance des reliefs en stuc. Ces recherches, comme on le sait, débutèrent dans les années 1830, mais l'attention était alors exclusivement fixée sur les bijoux les plus somptueux et sur la peinture des caveaux funéraires, de sorte que les mentions de décors de sarcophages en stuc ne sont pas nombreuses. On en trouve néanmoins déjà des reproductions dans l'album Antiquités du Bosphore Cimmérien édité en 1854 par le Musée de l’Ermitage ${ }^{13}$.

\footnotetext{
8. P. N. Šul'c, Mavzolej Neapolja Skifskogo.

9. N. I. Vinokurov, "Khudožestvenno-dekorativnye èlementy ukrašenij bosporskikh sarkofagov".

Io. O. M. Vorošilova, «Rel’efnye ukrašenija derevjannykh sarkofagov Fanagorii».

II. Théophraste, Traité des pierres, 62-69; Pline, Histoire naturelle, XXXV.153, 156, 157 et XXXVI.182-183; Pausanias, Description de la Grèce, I.40.3; Juvénal, Satires, II.5.

I2. G. I. Sokolov, "O portretnoj golovke iz gipsa v sobranii Gosudarstvennogo Èrmitaža» et Iskusstvo Bosporskogo carstva, p. 372; S. Ja. Berzina, «Proizvodstvo gipsovykh izdelij na Bospore», p. 246.

13. Antiquités du Bosphore Cimmérien conservées au Musée Impérial de l'Ermitage, t. 2, pl. LXXV et LXXVI.
} 
Les premières études sur les appliques en stuc s'attachaient à leur symbolique et à la recherche d'éventuels prototypes. S. A. Žebeljov a écrit sur un groupe de Niobides ${ }^{14}$, A. P. Ivanova sur une déesse anguiforme, des Éros, des Niobides, des masques de Méduse et des masques de théâtre ${ }^{15}$, N. P. Kivokurcev sur un Éros ${ }^{16}$. Récemment, E. N. Illarioškina a étudié l'arrière-plan mythologique de ces compositions ${ }^{17}$.

La datation des appliques et des tombes auxquelles elles se rapportent constitue une question à part. Pendant longtemps, elles ont été datées de l'époque hellénistique ${ }^{18}$. En 1904, V. V. Škorpil les a attribuées à l'époque romaine ${ }^{19}$. Sa chronologie a fini par s'imposer, et dans l'ensemble elle est encore admise aujourd'hui ${ }^{20}$. Les objets les plus importants pour la chronologie des appliques en stuc sont les hypogées de Tyritakè $^{21}$ et de Nymphée ${ }^{22}$. V. D. Blavatskij et M. M. Kobylina, qui ont étudié la nécropole de Tyritakè, la datent du I ${ }^{\text {er }}$ au III ${ }^{\mathrm{e}}$ s. apr. J.-C. ${ }^{23}$. S. Ja. Berzina a fait observer que la chronologie ne peut se fonder que sur le septième tombeau de la nécropole, dans lequel les sarcophages à décor

I4. S. A. Žebeljov, Pantikapejskie Niobidy.

15. A. P. Ivanova, «Khudožestvennye izdelija iz dereva i kosti», p. 423-426.

I6. N. P. Kivokurcev, «Bosporskaja gipsovaja statuètka Èrota».

I7. E. N. Illarioškina, «Bogi i geroi grečeskikh mifov v bosporskoj koroplastike».

I8. Compte rendu de la Commission Impériale Archéologique pour l'année 1863, p. 166 (L. Stephani) : entre la deuxième moitié du III e s. av. J.-C. et le début de notre ère; Compte rendu de la Commission Impériale Archéologique pour l'année 1875, p. 6 (L. Stephani): IV e-début du III e s. av. J.-C.; Otčjot Imperatorskoj Arkheologičeskoj Komissii za 1891, p. 32 sq. (A. A. Bobrinskij): III $\mathrm{I}^{\mathrm{e}} \mathrm{er}^{\mathrm{r}}$ s. av. J.-C.; S. A. Žebeljov, Pantikapejskie Niobidy, p. 18: pas avant le milieu du III s. av. J.-C.

I9. V. V. Škorpil, in Izvestija Imperatorskoj Arkheologičeskoj Komissii, 9, 1904, p. 164. 20. M. I. Rostovcev, Skifija i Bospor, p. 234 sq.: à appliques de stuc, après le $\mathrm{I}^{\text {er }}$ s. apr. J.-C., principalement au $\mathrm{II}^{\mathrm{e}}$ s.; N. P. Kivokurcev, "Bosporskaja gipsovaja statuètka Èrota", p. 282 : I $^{\text {er }}$ s. apr. J.-C., ne s'étendent pas jusqu'au II ${ }^{\mathrm{e}}$ s.; M. M. Kobylina, "Raskopki nekropolja Tiritaki v 1934 g.», p. 77 sq. : I ${ }^{\text {er }}$ II e s. apr. J.-C.; V. D. Blavatskij, «Raskopki nekropolja Tiritaki v 1933 g.», p. 63 et 72 : I Irr-III ${ }^{\mathrm{e}}$ s. apr. J.-C.; N. I. Sokol'skij, Antičnye derevjannye sarkofagi Severnogo Pričernomor'ja, p. 74 sq. : Ir $^{\mathrm{e}} \mathrm{II} \mathrm{e}^{\mathrm{e}}$ s. apr. J.-C.

2I. V. D. Blavatskij, "Raskopki nekropolja Tiritaki v 1933 g. ; M. M. Kobylina, «Raskopki nekropolja Tiritaki v 1934 g.».

22. N. L. Grač, Nekropol'Nimfeja.

23. M. M. Kobylina, "Raskopki nekropolja Tiritaki v 1934 g.", p. 77 sq. : I ${ }^{\text {er }}-I^{\mathrm{e}}$ s. apr. J.-C.; V. D. Blavatskij, "Raskopki nekropolja Tiritaki v 1933 g.», p. 63, 72 : I IrIII' s. apr. J.-C. 
en stuc sont disposés contre les murs et sont par conséquent plus anciens. Comme elle l'écrit:

La production des stucs qui nous intéressent ici se limite strictement au $\mathrm{I}^{\mathrm{er}}$ et au $\mathrm{II}^{\mathrm{e}}$ siècle. Il est très probable qu'elle ne se prolonge même pas dans la seconde moitié du $\mathrm{II}^{\mathrm{e}}$ siècle ${ }^{24}$.

La récente synthèse établie par N. K. Žižina corrobore cette datation ${ }^{25}$. Elle a observé que tous les décors en stuc découverts dans des ensembles funéraires de Panticapée et comprenant des marqueurs chronologiques datent de la deuxième moitié du ${ }^{\text {er }}$ s. apr. J.-C., tandis que les objets découverts à Nymphée ont une durée d'existence qui se prolonge jusquau milieu du $\mathrm{II}^{\mathrm{e}}$ siècle $^{26}$.

S. Ja. Berzina a écarté la possibilité de l'existence d'appliques de sarcophages en stuc à l'époque hellénistique, mais a néanmoins mentionné des objets d'argile découverts en 1853 dans des fouilles de sépultures hellénistiques de la nécropole de Théodosie ${ }^{27}$. Le sarcophage du mausolée de Néapolis des Scythes, orné d'appliques en stuc, est cependant daté du I ${ }^{\mathrm{er}}$ s. av. J.-C. et également attribué à un atelier du Bosphore Cimmérien ${ }^{28}$. En outre, les dernières recherches effectuées sur le kourgane de Gospital'nyj (Kertch) obligent à admettre l'existence d'appliques de stuc nettement plus anciennes encore, puisque dans ce kourgane a été dégagé un caisson de pierre contenant les restes d'un sarcophage de bois et d'un décor en stuc qui sont datés du milieu du IVe s. av. J.-C. Selon la reconstitution d'I. V. Rukovišnikova et D. V. Bejlin, c'était un sarcophage à fronton au milieu duquel était fixée une applique en médaillon avec une figure qui ne se laisse plus identifier ${ }^{29}$.

24. S. Ja. Berzina, «Proizvodstvo gipsovykh izdelij na Bospore», p. 254.

25. N. K. Žižina, Gipsovyj rel'efv pogrebal'nykh pamjatnikakh Evropejskogo Bospora pervykh vekov n. è., p. 136 sq.

26. Ibid., p. 65.

27. S. Ja. Berzina, «Proizvodstvo gipsovykh izdelij na Bospore», p. 251.

28. P. N. Šul'c, Mavzolej Neapolja Skifskogo, p. 26-30.

29. Exposé sur les fouilles du kourgane présenté au symposium du Musée-réserve d'histoire culturelle de Crimée orientale, "Archéologie et histoire du Bosphore», le 14 août 2018 à Kertch; dans leur publication, les auteurs datent la sépulture du troisième quart du $\mathrm{IV}^{\mathrm{e}} \mathrm{s}$. av. J.-C., mais ne mentionnent pas le relief en stuc. D. V. Bejlin, I. V. Rukovišnikova, N. F. Fedoseev, «Èlitnyj pogrebal'nyj pamjatnik Bosporskogo carstva kurgan “Gospital'nyj” ", p. 177. 
La première à s'intéresser aux aspects techniques de la confection des reliefs en stuc bosporans, S. Ja. Berzina a observé non seulement que le processus est analogue à celui de la production des terres cuites, mais encore que les artisans pouvaient utiliser les mêmes formes pour l'impression des terres cuites et le moulage des stucs ${ }^{30}$. Elle en conclut que les reliefs de stuc étaient confectionnés dans des ateliers de coroplastes bosporans (et suppose en outre que ces ateliers, au demeurant peu nombreux, étaient concentrés à Panticapée, ne retenant des autres centres de production possibles que Nymphée) ${ }^{31}$. S. Ja. Berzina a remarqué que plusieurs appliques de stuc et de terre cuite proviennent du même moule ${ }^{32}$. Cette observation est corroborée par la découverte, à Phanagorie, d'un moule pour la réalisation d'un relief à l'effigie de la Gorgone Méduse, qui avait servi non seulement à des moulages de stuc, mais aussi pour des masques de terre cuite et des masques d'argile non cuite $^{33}$. Il est significatif aussi que dans l'album du Musée de l'Ermitage Antiquités du Bosphore Cimmérien, de 1854, les reliefs de stuc figurent dans la même section que les terres cuites présentant des analogies avec eux $^{34}$.

S. Ja. Berzina a fait aussi une observation très importante sur la réalisation des appliques et la décoration des sarcophages directement dans les hypogées: "C'étaient les mêmes artisans qui ornaient les sarcophages d'appliques et avaient réalisé ces appliques. " ${ }^{35} \mathrm{~N}$. K. Žižina est elle aussi

30. S. Ja. Berzina, «Proizvodstvo gipsovykh izdelij na Bospore», p. 242.

3I. Ibid., p. 247, 250, 255. Il est connu que l'on peut rencontrer sur un même sarcophage des appliques de terre cuite et de stuc. Izvestija Imperatorskoj Arkheologičeskoj Komissii, 1913 p. 23: "Sur chacun des deux côtés ont été trouvées trois paires de Méduses de trois genres différents: deux paires en argile, enduites de stuc et ornées de peinture rose et noire; les quatre autres paires en stuc...»; Otčjot Imperatorskoj Arkheologičeskoj Komissii za 1891, p. 33 (A. A. Bobrinskij).

32. S. Ja. Berzina, «Proizvodstvo gipsovykh izdelij na Bospore», p. 247.

33. O. M. Vorošilova, "Rel'efnye ukrašenija derevjannykh sarkofagov Fanagorii», p. 87 sq., fig. 4.3 .

34. Antiquités du Bosphore Cimmérien conservées au Musée Impérial de l'Ermitage, t. 2, pl. LXXV et LXXVI.

35. S. Ja. Berzina, «Proizvodstvo gipsovykh izdelij na Bospore», p. 242: «L'artisan avait jeté sur place, derrière le caveau, les débris et les morceaux inutiles». V. V. Škorpil avait fait la même observation: Izvestija Imperatorskoj Arkheologičeskoj Komissii, 1903, p. 81. Dans Compte rendu de la Commission Impériale Archéologique pour l'année 1863, p. XII, il est question de la découverte d'appliques non seulement à l'intérieur du tombeau, mais aussi à l'extérieur, dans le remblai. 
d'avis que les appliques étaient confectionnées sur place, puisqu'à proximité des inhumations et lors du nettoyage des sarcophages, on a retrouvé des indices de fabrication et des pièces mal façonnées ${ }^{36}$. N. I. Vinokurov, auteur des recherches sur la nécropole d'Artezian, se range également à cet avis en faisant remarquer combien il aurait été périlleux d'acheminer vers le lieu d'inhumation des sarcophages ornés de fragiles appliques en stuc $^{37}$. Cette thèse permet de reconstituer le processus de décoration des sarcophages et sa logique, laquelle inclut les traits particuliers du rituel, conçu comme un acte symbolique de création du monde. La grande importance que présentent les moindres éléments du décor et leur structure hiérarchique n'est pas le fait du hasard.

Dans son étude fondamentale sur le travail du bois dans les cités antiques des régions septentrionales de la mer Noire, N. I. Sokol'skij distingue quatre types de sarcophages en bois. Selon lui, le troisième type était prédominant au $\mathrm{I}^{\mathrm{er}}$ et au $\mathrm{II}^{\mathrm{e}}$ siècle: des sarcophages en forme de temple avec des colonnes ou des arcades ${ }^{38}$. Or c'est justement au troisième type qu'il attribue les sarcophages ornés de reliefs en stuc ${ }^{39}$.

Les recherches approfondies de N. I. Sokol'skij sont notamment importantes pour la reconstitution de l'aspect extérieur des sarcophages à appliques de stuc, parce qu'il indique précisément les dimensions des détails et les particularités de construction des éléments conservés. Elles ont été complétées par des analyses chimiques des couleurs, effectuées pour la première fois au début des années 1960. Celles-ci ont montré que les couleurs utilisées pour les appliques de stuc sont peu différentes de celles des peintures murales des caveaux funéraires bosporans ${ }^{40}$. V. N. Kononov a établi la composition des différentes couleurs: le bleu est ce que l'on appelle bleu d'Égypte ou fritte d'Alexandrie, soit du verre bleu pilé rendu colorant par l'adjonction de cuivre; le noir est de la suie ou du charbon pilé; le blanc est du kaolin; l'orange est du sulfure naturel d'arsenic (réalgar), avec en surface de petits morceaux de feuille d'or;

36. N. K. Žižina, Gipsovyj rel'efv pogrebal'nykh pamjatnikakh Evropejskogo Bospora pervykh vekov n. è., p. 103 sq.; N. L. Grač, Nekropol' Nimfeja, p. 50-52, fig. 13.1-2.

37. N. I. Vinokurov, "Khudožestvenno-dekorativnye èlementy ukrašenij bosporskikh sarkofagov", p. 178.

38. N. I. Sokol'skij, Derevoobrabatyvajuščce remeslo v antičnykh gosudarstvakh Severnogo Pričernomor' ja, p. 120.

39. Ibid., p. 54-76.

40. V. N. Kononov, «K voprosu o tekhnike bosporskoj živopisi», p. 280. 
le rouge brique est de l'ocre rouge clair; le rose est de la pourpre dite végétale, extraite de la garance par précipitation des matières colorantes (alizarine et purpurine) de ses racines sur de l'alumine ${ }^{41}$.

G. I. Sokolov a remarqué que le stuc, de couleur neutre et convenant mieux que la terre cuite à l'application de peinture, permettait de créer des œuvres aux couleurs plus vives ${ }^{42}$. Selon A. P. Ivanova, les couleurs éclatantes, en plus de leur importance décorative, avaient pour vertu de renforcer la nature repoussante des appliques apotropaïques. En outre, la peinture avait parfois un caractère conventionnel, avec du bleu pour une bouche de masque de tragédie ou du rouge pour les yeux de la Méduse $^{43}$. N. I. Vinokurov s'est également intéressé à la symbolique des couleurs des reliefs de stuc ${ }^{44}$.

Nous devons maintenant à N. K. Žižina une nouvelle étude systématique des reliefs en stuc. Elle a consacré sa thèse aux ensembles les plus importants d'appliques provenant des nécropoles de Nymphée et de Panticapée (soit plus de 800 objets); dans plusieurs articles, elle a encore remarquablement développé le sujet. Elle examine toutes les questions clés concernant la fabrication, la répartition, la symbolique, la signification culturelle, le style, la datation et l'attribution de ces objets archéologiques.

Étudiant les ensembles archéologiques en relation avec les reliefs en stuc, N. K. Žižina, dans le sillage de N. I. Sokol'skij, met en évidence l'importance des appliques à la fois comme éléments de datation et comme révélateurs de la stratification sociale ${ }^{45}$. Elle a été la première à tenter de discerner des écoles locales, en comparant les reliefs en stuc de Nymphée et ceux de Panticapée ${ }^{46}$. Son analyse de la signification symbolique des appliques est d'une grande portée, de même que sa

4I. Ibid.

42. G. I. Sokolov, Iskusstvo Bosporskogo carstva, p. 407.

43. A. P. Ivanova, Iskusstvo antičnykh gorodov Severnogo Pričernomor' ja, p. 172 sq. et "Khudožestvennye izdelija iz dereva i kosti», p. 426 sq.

44. N. I. Vinokurov, "Khudožestvenno-dekorativnye èlementy ukrašenij bosporskikh sarkofagov", p. 177 sq.

45. N. K. Žižina, Gipsovyj rel'efv pogrebal'nykh pamjatnikakh Evropejskogo Bospora pervykh vekov n. è., p. 85; N. Jijina, "Nymphaion Necropolis in Bosporos", p. 199 sq.

46. N. K. Žižina, Gipsovyj rel'efv pogrebal'nykh pamjatnikakh Evropejskogo Bospora pervykh vekov n. è., p. 102 sq. et "Gipsovye tragičeskie maski kak èlement dekora bosporskikh derevjannykh sarkofagov I-II vekov». 
conclusion, selon laquelle le contenu expressif et le sens se sont perdus avec le temps, tandis que l'on continuait à reproduire comme des poncifs les schémas de composition ${ }^{47}$.

N. I. Sokol'skij distinguait trois groupes de motifs sur les appliques: les décors architecturaux, les motifs ornementaux, les figures apotropaïques et symboliques ${ }^{48}$. N. K. Žižina a établi une classification en cinq motifs fondamentaux, trente-deux types et pas moins de cinquante-trois variantes ${ }^{49}$. Les éléments des compositions décoratives se classent dans les groupes suivants: détails architecturaux, ornements végétaux, figures et masques d'animaux, représentations de personnages et de thèmes mythologiques. Elle observe que ces groupes font partie des motifs traditionnels des sarcophages décorés en marbre répandus à l'époque hellénistique et surtout à l'époque romaine.

\section{Ensembles archéologiques et reconstitutions}

N. I. Sokol'skij a observé que les sarcophages en bois des $\mathrm{I}^{\mathrm{er}}$ et $\mathrm{II}^{\mathrm{e}} \mathrm{s}$. apr. J.-C. ont pour structure de base un cadre constitué par les poteaux d'angle et les planches de l'architrave et du soubassement, qui forment une enveloppe sur tout le pourtour. Ce châssis est assemblé au moyen de rainures. Les poteaux d'angle, avec leur surface plane, sont conçus comme des pilastres. Le sarcophage ne repose habituellement pas directement sur son soubassement, mais sur des pieds qui prolongent les extrémités des poteaux d'angle ${ }^{50}$. La structure en gradins du soubassement et de la corniche, faits de plusieurs planchettes, est très caractéristique des sarcophages de cette époque. Sur presque tous les sarcophages de bois à toit en bâtière, la frise est décorée de planchettes à denticules ${ }^{51}$.

Les parois étaient faites d'une ou deux planches minces dont les extrémités étaient taillées pour se loger dans les rainures des poteaux. Sur un

47. N. K. Žižina, «Četyre gipsovye applikacii I-II vv. iz raskopok Nimfeja vo sobranii Ėrmitaža».

48. N. I. Sokol'skij, Antičnye derevjannye sarkofagi Severnogo Pričernomor' ja, p. 84.

49. N. K. Žižina, Gipsovyj rel'ef v pogrebal'nykh pamjatnikakh Evropejskogo Bospora pervykh vekov n. è., p. 12.

50. N. I. Sokol'skij, Derevoobrabatyvajuščce remeslo v antičnykh gosudarstvakh Severnogo Pričernomor' ja, p. 121 sq.

5I. N. I. Sokol'skij, Antičnye derevjannye sarkofagi Severnogo Pričernomor'ja, p. 81. 
sarcophage mis au jour en 1910 par exemple, lors des fouilles menées par V. V. Škorpil, une planche mesure $44 \mathrm{~cm}$ de largeur pour une épaisseur de $1 \mathrm{~cm}^{52}$.

Si les parois étaient ornées de colonnes, les dimensions de celles-ci dépendaient de la grandeur du sarcophage et de leur position. Celles que nous connaissons ont une hauteur comprise habituellement entre 37 et $40 \mathrm{~cm}$ (sur un sarcophage découvert en 1864 par A. E. Ljucenko sur le mont Mithridate, et un autre provenant des fouilles de V. V. Škorpil de 1910) (fig. 1). Certaines colonnes et colonnes engagées avaient une base en bois ou en stuc, d'autres n'avaient pas de base. Les chapiteaux étaient fabriqués selon deux techniques différentes. Dans le premier cas, qui se rencontre par exemple sur les colonnes du sarcophage du tombeau de la propriété Feldstein, le chapiteau était réalisé séparément et vraisemblablement en bois, puisque sur la face supérieure du fût, une petite cavité circulaire était destinée à recevoir une cheville de fixation, de même qu'il y en avait une sous la face inférieure pour la saillie de la base. Dans le second cas, le plus fréquent, le chapiteau était façonné en stuc. Les cannelures du fût, marquées au préalable, étaient taillées avec une gouge ${ }^{53}$. Les toits en bâtière reposaient sur un fronton triangulaire en planches.

Parmi les importantes recherches récentes sur les sarcophages de bois, il convient encore de mentionner le projet de D. V. Žuravljov et G. A Lomtadze sur l'ensemble funéraire découvert en 1890 par Ju. A. Kulakovskij au lieu-dit Glinišče à Kertch ${ }^{54}$. Le mobilier archéologique extrait de ce caveau funéraire est conservé au Musée national d'histoire à Moscou et à l'Ermitage, à Saint-Pétersbourg. Ju. A. Kulakovskij mit au jour un tombeau en moellons équarris contenant un sarcophage de bois avec un bouquet de fleurs décomposées sur le toit. À l'intérieur du sarcophage se trouvaient un cercueil enveloppé dans un tissu à motifs, le squelette et diverses offrandes funéraires: une corbeille contenant des noix, des boîtes en bois et de la vaisselle de verre. Le sarcophage était intact à l'exception de quelques planches et de quelques détails

52. N. I. Sokol'skij, Derevoobrabatyvajuščee remeslo v antičnykh gosudarstvakh Severnogo Pričernomor'ja, p. 121 sq.

53. N. I. Sokol'skij, Antičnye derevjannye sarkofagi Severnogo Pričernomor'ja, p. 82 et Derevoobrabatyvajuščee remeslo v antičnykh gosudarstvakh Severnogo Pričernomor'ja, p. 122.

54. D. V. Žuravljov, G. A. Lomtadze, «Pogrebenie s derevjannym sarkofagom iz nekropolja Pantikapeja». 
Fig. 1 - F. I. Gross. Sarcophage de bois découvert en 1864 dans la tombe en terre $\mathrm{n}^{\mathrm{o}} 11$ du mont Mithridate, à l'ouest du cimetière de la ville de Kertch. NA IIMK RAN, r. I, op. 1, d. 564, 1. 19. (C) Institut d'histoire de la culture matérielle, Académie des sciences de Russie, Saint-Pétersbourg, 2019.

sculptés qui avaient disparu, et sur le sol ont été recueillis des ornements en stuc ${ }^{55}$. Le mobilier découvert dans le caveau permet de le dater de la première moitié du $\mathrm{II}^{\mathrm{e}}$ s. apr. J.-C. ${ }^{56}$.

Le sarcophage est en bois de genévrier et a la forme d'un temple ${ }^{57}$. Ses dimensions sont les suivantes: longueur $210 \mathrm{~cm}$, largeur $75 \mathrm{~cm}$, hauteur $142 \mathrm{~cm}$. Il se rattache au type des «sarcophages à arcades». Il présente un soubassement à gradins, une architrave, une frise, une corniche, un toit en bâtière, des parois décorées de pilastres (cinq sur les parois longitudinales, un sur chaque paroi transversale) et des arcades entre les pilastres. Les angles sont mis en évidence par des planches plus épaisses qui avec les planches du soubassement et de l'architrave forment un châssis pour

55. Otčjot Imperatorskoj Arkheologičeskoj Komissii za 1890, p. 25.

56. D. V. Žuravljov, G. A. Lomtadze, «Pogrebenie s derevjannym sarkofagom iz nekropolja Pantikapeja», p. 37-39. n 77 .

57. N. I. Sokol'skij, Antičnye derevjannye sarkofagi Severnogo Pričernomor'ja, p. 59, 
les arcades. Sur la base des pilastres sont conservées des traces d'une couche de fond à la céruse de plomb; les appliques de stuc ont disparu ${ }^{58}$.

L'analyse générale de N. I. Sokol'skij est ainsi confirmée, et la description détaillée des vestiges de culte funéraire permet d'en reconstituer le déroulement.

La disposition des appliques de stuc est une question à traiter à part. Le sarcophage de bois à appliques de stuc représentant des Niobides découvert en 1874 est un témoin important ${ }^{59}$. Selon les auteurs de la première publication, une applique était encore en place, tandis que les autres avaient laissé des traces bien reconnaissables sur les parois du sarcophage. Les parois sont divisées par des colonnes ioniques dont les chapiteaux reposent sur les montées d'une arcade. Horizontalement, on distingue deux registres: celui du bas occupé par un treillage oblique de lattes de bois, tandis que dans le registre supérieur se trouvent des personnages inscrits dans les arcades. Les figures ont pour particularité d'être intentionnellement surélevées au-dessus de la ligne de la base des colonnes ${ }^{60}$.

Pour N. K. Žižina, sur les sarcophages en forme de temple avec des colonnes engagées en bois taillé, une frise, une corniche et un fronton, les détails architecturaux en stuc (bases, chapiteaux, acrotères et antéfixes) devaient être disposés selon leur fonction dans la construction. Quant à la disposition des grands éléments de décor, comme les masques de théâtre, il est possible de la déterminer par les restes du système de fixation sur le revers. Ceux qui présentent un revers fortement évidé et une base recourbée presque à angle droit servaient d'acrotères d'angle. Les masques sur lesquels le revers a une surface égalisée qui indique un joint avec une surface plane faisaient partie de diverses compositions en relief sur les parois longitudinales des sarcophages. Il est cependant difficile de reconstituer l'intégralité de ces compositions, parce qu'une grande partie du décor se trouve généralement en désordre sur le sol ${ }^{61}$.

58. D. V. Žuravljov, G. A. Lomtadze, «Pogrebenie s derevjannym sarkofagom iz nekropolja Pantikapeja", p. 34 sq.

59. Compte rendu de la Commission Impériale Archéologique pour l'année 1875, p. $5-15$.

6o. Ibid., p. 10 sq.

6I. N. K. Žižina, "Gipsovye tragičeskie maski kak èlement dekora bosporskikh derevjannykh sarkofagov I-II vekov». 
La reconstitution de l'aspect extérieur d'un sarcophage à appliques de stuc est possible seulement lorsqu'il existe une description détaillée de l'ensemble archéologique. Les tentatives ne sont donc pas nombreuses. La première a été celle de $\mathrm{O}$. I. Dombrovskij, qui a essayé de reconstituer l'aspect d'un sarcophage de bois découvert dans les fouilles de Néapolis des Scythes ${ }^{62}$. N. K. Žižina, quant à elle, pour ses hypothèses, s'est fondée sur le matériau des fouilles de la nécropole de Nymphée ${ }^{63}$. L'auteure de la présente contribution a également publié une petite esquisse d'après le matériau de la nécropole de Tyritakè ${ }^{64}$.

\section{Néapolis des Scythes}

Les fouilles menées en 1946 par N. N. Pogrebova dans le mausolée de Néapolis des Scythes ont amené à la découverte d'un sarcophage de bois très connu. Le mausolée se trouvait à l'entrée de la ville, adossé à l'enceinte avancée. Il se présentait sous la forme d'une construction de pierre sur un plan à peu près carré. À l'intérieur, en plus du sarcophage, ont été découvertes 37 boîtes en bois de pin, décomposées, contenant des ossements, et un tombeau en pierre.

Après la décomposition du sarcophage sous la couche de débris des murs en brique crue, les détails du relief se sont imprimés dans l'argile. De ces empreintes, on a effectué des moulages en plâtre. Les vestiges du sarcophage ont été précisément relevés, mesurés et dessinés. Ces travaux ont été dirigés par O. I. Dombrovskij et E. A. Bolotnikova. Ils ont abouti au dessin de reconstitution du sarcophage par O. I. Dombrovskij ${ }^{65}$ (fig. 2).

Lossature du sarcophage était faite en pin et les éléments décoratifs sculptés en cyprès. Il se composait d'un piédestal allongé reposant sur quatre pieds sculptés et d'un cercueil rectangulaire à toit à quatre pans à terrasse faîtière.

Le soubassement était décoré de colonnes sculptées à cannelures reposant sur une base circulaire: huit sur les faces longitudinales, six

62. P. N. Šul'c, Mavzolej Neapolja Skifskogo, p. 25-30, pl. VIII-IX.

63. N. K. Žižina, «Kompleks gipsovykh rel'efov iz zemljanogo sklepa nekropolja Nimfeja i voprosy rekonstukcii dekora bosporskikh derevjannykh sarkofagov rimskogo vremeni».

64. L. I. Akimova, O. V. Tuguščeva (otv. red.), Šedevry antičnogo iskusstva, p. 416419, no 150 , fig. 50.

65. P. N. Šul'c, Mavzolej Neapolja Skifskogo, p. 13, fig. 11-13, pl. VIII-IX. 
Fig. 2 - Sarcophage de bois du mausolée de Néapolis des Scythes. Face transversale. Aquarelle de reconstitution par O. I. Dombrovskij. D’après P. N. Šul'c, Mavzolej Neapolja Skifskogo, Moskva, 1953. 


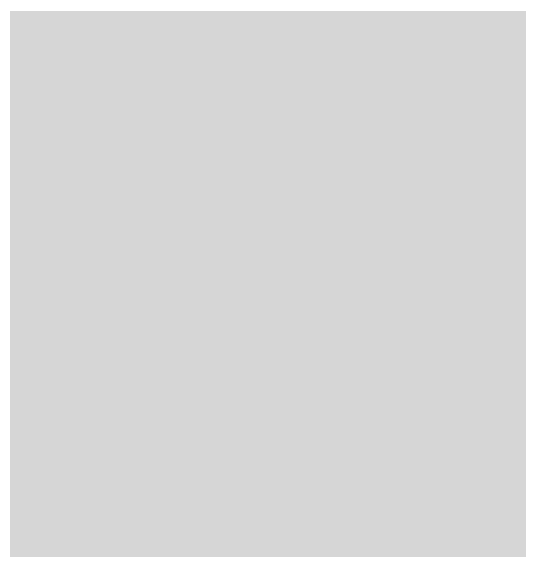

Fig. 3 - Cnide. Tombeau au lion, vers 325-300. Reconstitution de R. Pullan.

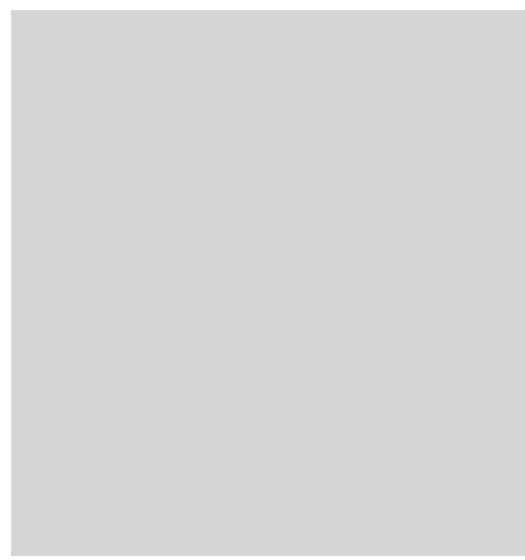

Fig. 4 - Amphipolis. Monument funéraire, deuxième moitié du $\mathrm{IV}^{\mathrm{e}} \mathrm{s}$. av. J.-C. Photographie ancienne.

sur les faces transversales. Pour les chapiteaux, non conservés, le dessin de reconstitution propose un style corinthien conventionnel. Entre les chapiteaux étaient peut-être placés des médaillons ou des masques en stuc; du moins des fragments de stuc ont-ils été retrouvés près du sarcophage. Les angles étaient mis en évidence par des colonnes posées sur des figures sculptées de griffons et de sphinx; au-dessus s'élevaient des colonnes élancées à couronnement en pomme de pin. Le soubassement était enduit d'un vernis blanc, les colonnes (celles du soubassement et celles des angles) étaient dorées. Le couronnement des colonnes d'angle était enduit d'un vernis bleu foncé.

Les parois du cercueil étaient décorées d'une guirlande sculptée de branches portant des feuilles et des fruits, et serrée par des rubans. Un vernis rouge foncé recouvrait les parois, tandis que la guirlande était dorée. Une autre guirlande ornait le couvercle du cercueil, avec des rubans dorés, des fleurs vernies de bleu clair et de blanc qui se détachaient nettement sur le fond rose.

Sur la terrasse faîtière se trouvaient peut-être des figures sculptées en bois polychrome, représentant un griffon à tête de lion et un sphinx, qui font penser aux monuments connus sur la presqu'île de Cnide, à Chéronée et à Amphipolis ${ }^{66}$ (fig. 3 et 4).

66. I. Jenkins, Greek architecture and its sculpture in the British Museum, p. 228-231. 
L'inhumation est supposée avoir eu lieu entre le $\mathrm{I}^{\mathrm{er}}$ s. av. J.-C. et le $\mathrm{I}^{\mathrm{er}}$ s. apr. J.-C. Sous le sarcophage a en effet été trouvée une monnaie chersonésite datant d'entre la fin du II et la première moitié du ${ }^{\mathrm{er}} \mathrm{s}$. av. J.-C. ${ }^{67}$. Dans cet ouvrage complexe, éclatant et somptueux, nous pouvons donc voir le prototype hellénistique des sarcophages ultérieurs à reliefs de stuc. Il est important de faire observer les trois caractéristiques essentielles de ce sarcophage: premièrement, une composition en plusieurs registres avec des frises séparées par des couronnements moulurés; deuxièmement, la juxtaposition de figures en ronde-bosse, de reliefs (dont certains en stuc) et de peintures; et troisièmement, la "colonnade» décorative dans la partie inférieure et les guirlandes fleuries dans la partie supérieure. La peinture a un coloris hellénistique: fond rose et rouge avec des touches bleu clair et dorées.

Les variantes qui se répandront plus tard dans le Bosphore Cimmérien utiliseront le soubassement comme base de la composition, tandis que les frises à guirlandes se transformeront en éléments distincts de décor végétal.

\section{Nymphée}

Les fouilles de la nécropole de Nymphée ont été effectuées de 1973 à 1977 sous la direction de N. L. Grač. Les sépultures datent en majorité du I ${ }^{\text {er }}$ s. av. J.-C. au III s. apr. J.-C. ${ }^{68}$. On a mis au jour en tout vingttrois ensembles funéraires, comprenant d'une part des tombes creusées en pleine terre, et de l'autre des hypogées. Quelques-uns de ces hypogées contenaient des sarcophages de bois à décor en stuc; dans les autres, le corps était étendu sur une épaisse couche d'algues.

Il est attesté que les sarcophages ou les lits de bois étaient ornés de reliefs en stuc enduits de couleur blanche ${ }^{69}$. Le bois s'était mal conservé, mais les appliques découvertes sur la terre autour des squelettes se trouvaient dans une disposition précise. Le mobilier archéologique recueilli lors de ces fouilles de la nécropole de Nymphée forme un ensemble de près de deux mille unités.

67. P. N. Šul'c, Mavzolej Neapolja Skifskogo, p. 29 sq.

68. N. L. Grač, «Raskopki nekropolja Nimfeja» (1975 et 1978) et "Raskopki nekropolja Nimfeja v 1973-74 gg. ».

69. N. Jijina, "Nymphaion Necropolis in Bosporos", p. 204. 
Pour la chronologie et la reconstitution des sarcophages de bois à reliefs en stuc, les objets découverts dans le caveau funéraire K-26 sont particulièrement importants. Ce caveau est daté par des monnaies, par de la vaisselle de verre et par de la céramique entre le deuxième quart du $\mathrm{I}^{\mathrm{er}}$ et la première moitié du II ${ }^{\mathrm{e}}$ s. apr. J.-C. ${ }^{70}$. Il comprenait un dromos et une chambre funéraire à parois inclinées. Les parois montraient encore des vestiges de peinture de couleur blanche, jaune et bleu clair. Neuf sépultures au total ont été retrouvées dans le caveau; certaines reposaient sur un podium avec une couche d'herbes aquatiques. La tombe $\mathrm{n}^{\circ} 9$ contenait de petits restes de planches de bois à enduit, ce qui permet d'admettre l'existence d'un sarcophage; dans les tombes $n^{\text {os }} 5,6$ et 7, les restes de sarcophages conservés étaient plus caractérisés.

Des fragments des décors des sarcophages ont subsisté. Il s'agit principalement de parties de corniches à denticules, qui permettent de supposer que les sarcophages présentaient un décor d'ordres d'architecture et par conséquent se rattachent au type des sarcophages-temples. Dans la tombe $\mathrm{n}^{\circ} 6$ (d'un individu de sexe masculin), on a constaté sur le sol en terre de la chambre funéraire une cavité formée par un pied de sarcophage, d'une dimension de $22 \times 5 \mathrm{~cm}$, pour une profondeur de $10 \mathrm{~cm}$. On a également découvert les traces qu'avaient laissées en s'effondrant des colonnes engagées décoratives; d'après ces traces, la hauteur des colonnes est estimée à $20-25 \mathrm{~cm}$. Leur largeur est établie à partir du diamètre intérieur des bases de stuc, soit environ $6 \mathrm{~cm}$. Des cannelures étaient imprimées sur la face concave des bases. Aux angles s'élevaient probablement des colonnes cylindriques terminées en haut par des chapiteaux et en bas par des bases sur trois quarts de leur circonférence. Selon N. K. Žižina, c'est un sarcophage découvert en 1864 par A. E. Ljucenko, ainsi qu'un autre exemplaire conservé à la Collection des antiquités de Berlin qui offrent le plus de similitudes avec ceux de Nymphée ${ }^{71}$. Il est intéressant

70. N. K. Žižina, Gipsovyj rel'ef v pogrebal'nykh pamjatnikakh Evropejskogo Bospora pervykh vekov n. è., p. 67-80, 108-114 et «Kompleks gipsovykh rel'efov iz zemljanogo sklepa nekropolja Nimfeja i voprosy rekonstukcii dekora bosporskikh derevjannykh sarkofagov rimskogo vremeni»; N. L. Grač, Nekropol' Nimfeja, p. 163-171.

7I. N. K. Žižina, Gipsovyj rel'efv pogrebal'nykh pamjatnikakh Evropejskogo Bospora pervykh vekov n. è., p. 113; N. I. Sokol'skij, Antičnye derevjannye sarkofagi Severnogo Pričernomor' $j a$, $\mathrm{n}^{\text {os }} 91-92$, pl. 34.1-2 et 37.1-2. 
de noter en outre que l'emploi des colonnes comme élément structurant se rencontre également sur les parois des sarcophages peints ${ }^{72}$.

Dans les environs des sarcophages détruits fut mise au jour une grande quantité de reliefs en stuc. Ils peuvent être regroupés en trois ensembles. Se rattachent au sarcophage $\mathrm{n}^{\mathrm{o}} 1$ : cinq fleurs de lotus, trois compositions végétales en hauteur, trois masques de tragédie, trois têtes de Gorgone, deux feuilles miniatures; au sarcophage $\mathrm{n}^{\mathbf{0}} 2$ : cinq fleurs de lotus, trois figures d'Attis, une figure de divinité anguipède, quatre palmettes à cœur ovale peint en rose, quatre masques de tragédie, un acrotère massif en palmette; au sarcophage $\mathrm{n}^{\mathrm{o}} 3$ : une figure de Niobide, neuf masques de tragédie, deux fleurs de lotus, six compositions végétales en hauteur, deux grandes rosettes à nombreux pétales, neuf disques à bouton, quatre bases de colonnes engagées à cannelures. Près des deux premiers sarcophages ont également été trouvés douze disques à bouton et seize chapiteaux ou bases de colonnes engagées en bois à cannelures.

L. Olejnikova a effectué en 1981 une analyse des couleurs. Le pigment bleu (lotus) est de la fritte d'Alexandrie; le brun (chapiteau), un ocre naturel; l'orange (masques de tragédie), du minium de plomb; le noir (masques de Gorgone), du charbon; le rose (masques de tragédie), une craie avec du carmin extrait de la cochenille farineuse ${ }^{73}$.

N. K. Žižina reconstitue trois variantes de disposition des décors sur les parois des sarcophages ${ }^{74}$. Les appliques sont toujours disposées dans les entrecolonnements. Dans la variante "a» alternent des masques de Gorgone et des masques de théâtre; dans la variante «b», des fleurs de lotus et des masques de théâtre. La variante " $\mathrm{V}{ }^{75}$ présente une composition à deux registres dans les entrecolonnements. Les figures dépareillées sont essentielles. Elles sont disposées dans les entrecolonnements du

72. Peinture à l'intérieur d'un sarcophage découvert par E. K. Dumberg en 1900 au lieu-dit Glinišče: M. Rostovtseff, La peinture décorative antique en Russie méridionale, pl. XCII-XCV.

73. N. K. Žižina, Gipsovyj rel'efv pogrebal'nykh pamjatnikakh Evropejskogo Bospora pervykh vekov n. è., p. 108.

74. N. K. Žižina, «Kompleks gipsovykh rel'efov iz zemljanogo sklepa nekropolja Nimfeja i voprosy rekonstukcii dekora bosporskikh derevjannykh sarkofagov rimskogo vremeni ", p. 162, fig. 20-22 et Gipsovyj rel'ef v pogrebal'nykh pamjatnikakh Evropejskogo Bospora pervykh vekov n. è., p. 113 sq.

75. En translittération, « $\mathrm{a}$ », « $\mathrm{b}$ » et « $\mathrm{V}$ » sont les trois premières lettres de l'alphabet russe (ndt). 
milieu et représentent des divinités anguipèdes et des Niobides. Dans les angles sont supposés s'être trouvés des figures d'Attis, des palmettes (variante «b») ou des masques de théâtre (variante "v»). Le stylobate est orné de feuilles bicolores (variante "a») ou de nombreux disques à bouton (variantes «b» et « $\mathrm{v} »)$. Le faîte du toit est couronné d'imposants acrotères en forme de palmette (variante $« \mathrm{~b} »)$. Un aspect important de l'interprétation de Žižina est qu'elle considère les faces latérales comme secondaires et y reconstitue un décor formé principalement d'ornements végétaux massifs: fleurs de lotus (variante «a»), rosettes à fleurs multiples (variante «V»); c'est seulement sur la variante « $b$ » que l'on y voit des figures d'Attis. Ces reconstitutions ont pour autres caractéristiques importantes que les éléments y sont montrés selon un système ordonné, qu'ils suivent une disposition en frises et qu'ils renforcent la symétrie et le rythme d'alternance des appliques similaires.

\section{Artezian}

De 1999 à 2007, les fouilles menées par N. I. Vinokurov dans la nécropole du site d'Artezian, sur le littoral criméen de la mer d'Azov, ont permis la découverte de plus de 245 monuments funéraires, dont huit hypogées monumentaux en pierre ${ }^{76}$. Les tombeaux les plus somptueux, avec des inhumations en sarcophages décorés, avaient malheureusement été détruits par des pillards. Sur le fond des tombes avaient subsisté des cavités correspondant aux pieds coniques des sarcophages et mesurant $30 \times 50 \mathrm{~cm}$. Les sarcophages avaient donc une forme de caisse allongée posée sur des pieds élevés; leurs dimensions étaient d'environ 180-210 x $50-80 \mathrm{~cm}^{77}$.

La tombe $\mathrm{n}^{\circ} 35$ (de la fouille de 2001), pillée, contenait les restes de sarcophage les mieux préservés. Le fragment conservé a une longueur de $138-154 \mathrm{~cm}$, une largeur de $64 \mathrm{~cm}$, une hauteur de $26-32 \mathrm{~cm}$; l'épaisseur des bords varie entre 8 et $14 \mathrm{~cm}$; la largeur de l'espace intérieur est de 39 à $42 \mathrm{~cm}$. Le sarcophage avait à l'origine une longueur que l'on peut estimer à 180-190 cm au moins. Sur le fond, les planches longitudinales étaient renforcées par des traverses fixées au moyen de chevilles de bois.

76. N. I. Vinokurov, «Khudožestvenno-dekorativnye èlementy ukrašenij bosporskikh sarkofagov", p. 171 sq.

77. Ibid., p. 172. 
Il a été possible d'observer trois de ces traverses. Les planches qui ont servi à confectionner le sarcophage avaient une épaisseur de 2,5-4 cm. Les pieds du sarcophage étaient cylindriques ou tronconiques (hauteur environ $15-20 \mathrm{~cm}$, diamètre dans la partie inférieure environ $14 \mathrm{~cm}$ ). Sur les planches du sarcophage ont été fixées des traces de peinture rose et rouge.

Ce tombeau a fourni une grande quantité de reliefs en stuc dont la surface avait conservé des restes de couleur rose crème, bleu vif et noir. Il s'y trouvait notamment quatre protomés de Déméter (k.o. 28, 59), six protomés de Korè (k.o. 58), quatre reliefs à tête de Gorgone (k.o. 57), dix-sept rosettes circulaires (k.o. 53), vingt rosettes circulaires à tenon saillant (k.o. 54), quatre appliques en forme de serrures massives de forme cylindrique (k.o. 55), trois petits pains (?) sur un pied (k.o. 56), quatre bases moulurées (k.o. 52) ${ }^{78}$. Les traits du visage de Déméter et de Korè sont marqués à la couleur noire, la surface extérieure des "petits pains» est couverte d'un réseau de lignes imprimé avant le durcissement du stuc par un objet métallique à lame très fine et tranchante.

Dans la tombe féminine $\mathrm{n}^{\mathrm{o}} 106 / 2003$, du I ${ }^{\mathrm{er}}$ s. apr. J.-C., ont été découverts plus d'une trentaine de disques à bouton (que N. I. Vinokurov appelle "appliques phalloïdes»; k.o. 41) ${ }^{79}$, quatre bases avec des restes de peinture rose et bleu clair (k.o. 42), deux bucranes avec des restes de peinture noire, rose et brun-rouge, trois masques de Méduse fragmentaires ornés de peinture de couleur noire, bleu foncé et cramoisie (k.o. 47-49). Il est intéressant d'observer que sur le mufle du taureau, au-dessus des narines, sont dessinées en rose deux courroies, auxquelles devaient être attachées des brides passant par des anneaux, et sur le front, entre les cornes, deux losanges inscrits l'un dans l'autre, de couleur brunrouge (k.o. 43). Les cornes étaient peintes du même noir que le dessin des yeux, tandis que les oreilles et le fond de la tête étaient roses ${ }^{80}$.

78. Ibid., p. 173, fig. 1.1.

79. Les auteures du catalogue des appliques du Louvre y voient «une schématisation de rosettes avec un grain de raisin central - symbole de vie éternelle»: P. Pinelli, A. Wąsowicz, Catalogue des bois et stucs grecs et romains provenant de Kertch, p. 122.

8o. N. I. Vinokurov, «Khudožestvenno-dekorativnye èlementy ukrašenij bosporskikh sarkofagov", p. 173, fig. 1-2. 
N. I. Vinokurov suppose que les bases moulurées décoraient les pieds des sarcophages ${ }^{81}$. Il paraît toutefois plus vraisemblable de les mettre en relation avec les colonnes latérales.

Malgré quelques différences formelles, cet ensemble de figures en stuc, avec ses particularités stylistiques et techniques, est assez analogue à ceux de Panticapée, de Nymphée et de Tyritakè. Cela conforte l'hypothèse émise plus haut et selon laquelle, à l'époque romaine, les cités satellites de Panticapée étaient desservies, pour la confection et le décor des sarcophages, par quelques ateliers de la capitale, ce qui explique leur aspect uniforme.

\section{Phanagorie}

Les ensembles de reliefs de stuc décoratifs découverts sur la côte asiatique de la baie de Kertch sont d'un grand intérêt.

En 1988, A. A. Zavojkin a mené la fouille des tombes en pleine terre de la nécropole Ouest de Phanagorie. Les tombes $n^{\text {os }} 1 / 1988$ et $5 / 1988$ contenaient des sarcophages à ornements de stuc. O. M. Vorošilova a observé qu'il s'agit dans les deux cas de sépultures en fosse dite «à épaulement ", c'est-à-dire avec un ressaut destiné à supporter une couverture ${ }^{82}$.

Durant l'été 2011, dans un secteur de la nécropole Orientale de Phanagorie, a été découverte la tombe ${ }^{\circ} 165 / 2011$, qui contenait un sarcophage de bois avec douze masques de terre cuite de la Gorgone Méduse $^{83}$. Sur quelques exemplaires, on a constaté des traces de couleur rose. Les reliefs étaient répartis à raison de quatre par côté longitudinal du sarcophage, et deux par côté transversal ${ }^{84}$.

Dans l'ensemble, les appliques de Phanagorie présentent les mêmes caractéristiques typologiques que celles de Panticapée, mais le travail est celui d'un autre atelier. Les masques de Méduse, par exemple, s'inscrivent dans des médaillons circulaires et se distinguent par le contour ovale du visage, encadré par de courtes mèches-pétales et des traits fins en faible relief. À Panticapée, au contraire, les masques n'ont pas de cadre

81. Ibid.

82. O. M. Vorošilova, «Rel'efnye ukrašenija derevjannykh sarkofagov Fanagorii», p. 88 .

83. Ibid., p. 87, fig. 4.1-2.

84. Ibid., p. 88. 
en médaillon et ils se distinguent par la forme circulaire des visages, qui montrent des joues saillantes et une surface au modelé expressif.

\section{Tyritakè}

La collection du Musée des Beaux-Arts Pouchkine possède des ensembles exceptionnels de reliefs en stuc provenant des fouilles effectuées en 1933 dans la nécropole de Tyritakè (actuellement Kamyš-Burun). Une campagne commune du Musée et de l'Académie d'histoire de la culture matérielle, sous la direction de V. D. Blavatskij, aboutit à la découverte de huit tombeaux d'époque romaine qui, à l'exception d'un seul, présentaient tous un grand hypogée en terre. Un corridor-dromos menait à chacun des caveaux, dont l'entrée était fermée par une grande dalle rectangulaire. Les chambres funéraires contenaient chacune plusieurs sépultures. Des traces de bois attestaient la présence, dans plusieurs de ces tombes, d'un cercueil, qui avait été posé sur un banc de terre à une hauteur atteignant le mètre. Sur le toit d'un des sarcophages, des branches de cyprès étaient conservées, tandis que des herbes aquatiques (zostères) en recouvraient le fond. Le sol des chambres funéraires et les bancs étaient couverts d'une couche de coquillages et de galets. Les murs des chambres funéraires étaient vraisemblablement enduits de blanc ${ }^{85}$.

Ces caveaux funéraires présentent une grande ressemblance avec le tombeau K-26 de la nécropole aux hypogées de Nymphée, décrit ci-dessus. Il s'agit également d'un caveau en terre, dans lequel étaient disposés des sarcophages de bois sur des bancs de terre. On observe là aussi une couche d'herbes aquatiques et des fragments d'enduit mural, de couleur blanche, jaune et bleu clair. Et c'est précisément dans ce caveau que le mobilier comprend aussi des fragments de décor en stuc.

Les ensembles de reliefs en stuc les plus intéressants proviennent des tombeaux $n^{o s} 2$ et 7 . Dans le premier, on recense trois protomés de Silène, trois masques de lion, des disques à bouton entiers ou fragmentaires, enfin des fragments d'autres ornements (volutes, éléments végétaux, boules, etc.). Dans la chambre funéraire $\mathrm{n}^{\circ} 7$ ont été trouvés les vestiges de quatre sarcophages de bois et des ornements de stuc: pour le premier sarcophage, un masque, un protomé, des fragments de grands acrotères d'angle et des ornements à bouton; pour le second sarcophage,

85. V. D. Blavatskij, «Raskopki nekropolja Tiritaki v 1933 g.». 
des disques à bouton, de petits protomés, deux figures d'Éros chevauchant des dauphins, un petit acrotère d'angle, un revêtement de pieds en bois tourné, une figure d'oiseau et des fragments d'ornements végétaux; pour le troisième sarcophage, des disques à bouton, un petit acrotère, des fragments de figures de petits garçons, des fragments d'un masque de Méduse et d'un masque de tragédie, et des revêtements de base moulurée; pour le quatrième sarcophage, des disques à bouton, des figures d'oiseaux, un petit acrotère, des masques de Méduse, des masques de tragédie, quatre acrotères d'angle ajourés fragmentaires, deux grands acrotères ajourés plats et une grande quantité de fragments d'autres ornements.

La collection du Musée des Beaux-Arts Pouchkine est unique par l'exhaustivité et la précision du relevé archéologique de chaque élément de l'ensemble. Il est de ce fait permis d'attribuer les différents éléments avec une assez grande certitude à un sarcophage précis, et même, dans certains cas, de les attribuer à l'une ou l'autre des faces du sarcophage. Nous avons donc là suffisamment de matériau pour une reconstitution approximative du décor extérieur de ces objets, et cela malgré la disparition presque complète du fond en bois, qui n'a pas laissé de traces archéologiques.

Nous avons pu élaborer une reconstitution de l'un de ces sarcophages, le quatrième du tombeau $n^{\circ} 7$ (fig. 5 et 6). Pour base de cette reconstitution, nous avons choisi le type du sarcophage-temple à toit en bâtière, frontons et colonnes engagées en bois taillé, caractéristique du Bosphore Cimmérien. Avec sa longueur de $215 \mathrm{~cm}$ et sa largeur de $100 \mathrm{~cm}$, ce sarcophage a des dimensions légèrement supérieures à la moyenne. L'ossature est constituée par les montants d'angle et les planches de l'architrave et du soubassement, qui leur sont liées. La plupart des éléments en stuc ont une épaisseur de 2,5-3 cm; comme ils étaient fixés sur la tranche des planches, c'est cette valeur que nous avons retenue pour l'épaisseur des planches (de même, nous avons observé une épaisseur de planches de $5 \mathrm{~cm}$ dans la nécropole de Nymphée et de 2,5-4 cm à Artezian).

La présence de fragments de volutes ioniques en bois et de bases de colonnes moulurées en stuc nous permet de reconstituer une frise à colonnes ioniques sculptées. Les fûts des colonnes étaient en bois taillé et décoré de cannelures dont les empreintes sont restées visibles sur les éléments de stuc des bases. Ces éléments du sarcophage $n^{\circ} 4$, d'une 
Fig. 5 - Sarcophage de la nécropole de Tyritakè (tombe $n^{\circ} 7$, sarcophage $n^{\circ} 4$ ). Reconstitution d'O. Ju. Samar. 
Fig. 6 - Reliefs de stuc et décorations en bois du sarcophage de Tyritakè (tombe $\mathrm{n}^{\circ} 7$, sarcophage ${ }^{\circ}$ 4). (C) Musée d'État des Beaux-Arts Pouchkine, Moscou, 2019. 
épaisseur de moins de $1 \mathrm{~cm}$, avaient une surface unie et étaient conservés en de nombreux petits fragments. Il faut vraisemblablement supposer qu'ils étaient soutenus par des supports de bois. Comme ces fragments ne permettent pas d'établir le profil des bases des angles, nous avons choisi de ne pas reconstituer des colonnes d'angle, quoique nous sachions précisément que le sarcophage $\mathrm{n}^{\circ} 2$ du même tombeau en avait (il subsistait une base en stuc peinte en bleu clair et présentant un profil d'une complexité convenant à une base). Les proportions des colonnes ont été reconstituées d'après les vestiges découverts dans le caveau K-26 de la nécropole de Nymphée (longueur $25 \mathrm{~cm}$, diamètre $6 \mathrm{~cm}$, cf. supra).

Il s'agit d'un exemple très rare de chapiteaux ioniques en bois conservés. Sur le sarcophage de Néapolis des Scythes, les chapiteaux sont supposés corinthiens, et la nécropole de Nymphée n’a livré aucun vestige de chapiteaux. N. K. Žižina estime qu'il est difficile de reconstituer des chapiteaux ioniques et propose d'y voir plutôt des chapiteaux doriques ${ }^{86}$. De plus, l'ordre ionique est le plus caractéristique du Bosphore Cimmérien: des crochets de volutes ont été observés sur le sarcophage découvert en 1864 et sur le sarcophage aux Niobides des fouilles de Ljucenko, de $1874^{87}$. Les chapiteaux présentent des paires de volutes planes en bois (largeur $8 \mathrm{~cm}$, hauteur 3-4 cm, épaisseur 0,5-0,7 cm).

L'ensemble comprend des acrotères de deux types différents: des acrotères triangulaires en hauteur pour les angles (hauteur $28 \mathrm{~cm}$, largeur $13 \mathrm{~cm}$ ), et des acrotères à surface plane (hauteur $23,5 \mathrm{~cm}$, largeur $22,5 \mathrm{~cm}$ ). Les acrotères à surface plane ne tiennent pas d'eux-mêmes et sont en fait des appliques. V. P. Tolstikov pense à juste titre que l'on a confectionné une planche de support pour ces acrotères et que ceux-ci couronnaient le fronton.

Des oiseaux étaient représentés par des figures sphériques (hauteur $5 \mathrm{~cm}$, longueur $5,5 \mathrm{~cm}$ ). Ils étaient vraisemblablement posés sur le faite du toit. Quatre exemplaires conservés présentent un fond plat, ce dont nous pouvons conclure qu'ils étaient posés sur le faîtage. Un autre a un fond circulaire évidé et était par conséquent destiné à être fixé sur un élément saillant, probablement sur la planche qui servait de fond à un des

86. N. K. Žižina, Gipsovyj rel'efv pogrebal'nykh pamjatnikakh Evropejskogo Bospora pervykh vekov n. è., p. 109.

87. N. I. Sokol'skij, Antičnye derevjannye sarkofagi Severnogo Pričernomor' ja, $\mathrm{n}^{\text {os }} 80$, 91, pl. 32.6-7 et 37.1-2. 
acrotères de couronnement ${ }^{88}$. Sur ces figures d'oiseaux subsistaient des restes de couleur bleu clair.

Les masques de tragédie servaient vraisemblablement d'antéfixes (hauteur $9 \mathrm{~cm}$, largeur $8 \mathrm{~cm}$, profondeur $2,5 \mathrm{~cm}$ ). Les masques en stuc n'ont pas toujours des caractéristiques d'antéfixes, mais c'est assurément le cas des exemplaires de Tyritakè. La cavité intérieure est adaptée à une planche d'une épaisseur de $3 \mathrm{~cm}$; le fond plat est prévu pour la pose sur les planches supérieures de l'ossature.

Les masques en stuc de la nécropole de Tyritakè se distinguent par leur forme rectangulaire, un large front et une bouche à petite ouverture arrondie de part en part. Ils présentent un profil grec rectiligne. Les traits du visage sont plastiquement riches et modelés avec finesse: les sourcils et les pommettes sont élevés pour être en évidence, la profonde cavité de la bouche se joint de manière particulière à la forme du nez, la coiffure montre une haute protubérance dirigée vers l'avant. Les yeux sont entourés de lignes de couleur noire, la même qui dessine le cercle des prunelles. Les visages sont peints en orange. Les masques, dans l'ensemble du décor du sarcophage, avaient sans doute une fonction apotropaïque.

Un principe analogue s'observe dans la qualité de l'ornementation et des masques de Méduse (hauteur $12 \mathrm{~cm}$, largeur 12,5 cm). La collection du Musée possède un masque de Méduse entier et une série de fragments de type très proche. Ils se caractérisent par leur planéité et des détails rendus avec précision en faible relief ${ }^{89}$. On peut remarquer la finesse des traits du visage et la liberté du dessin des boucles des cheveux. Des restes de couleur bleu clair et jaune sont visibles à la surface. Les masques étaient peut-être posés sur les frontons, à la manière de nombreux exemples bien connus (le temple C de Sélinonte, le temple d'Artémis à Corcyre, un sarcophage romain du British Museum ${ }^{90}$, ou un relief romain de la Collection des antiquités des musées d'État de Berlin ${ }^{91}$ ).

Le seul emplacement possible pour les disques à bouton est sur le châssis au niveau du stylobate (hauteur $3-4 \mathrm{~cm}$, diamètre $3 \mathrm{~cm}$ ). Leur diamètre est également adapté à l'épaisseur supposée de la planche.

88. Ces oiseaux ne sont pas reproduits sur la reconstitution du sarcophage.

89. Des masques de Méduse de ce type se rencontrent sur des antéfixes de terre cuite de Panticapée, datant du IV s. av. J.-C.: V. F. Gajdukevič, «Istorija antičnykh gorodov Severnogo Pričernomor'ja», p. 110, fig. 36.

90. Londres, $\mathrm{n}^{\circ}$ inv. 1861,0220.3.

91. Berlin, no inv. SK 921. 
La composition était vraisemblablement structurée selon des axes sur lesquels s'alignaient les masques-antéfixes, les colonnes et les disques à bouton du stylobate. Les autres éléments décoratifs - principalement des rameaux à têtes de lion - étaient répartis dans les entrecolonnements, ainsi que le suppose N. K. Žižina en se fondant sur les fragments de la nécropole de Nymphée.

D'après les vestiges archéologiques, il semble qu'il était d'usage d'enduire le sarcophage d'une couche blanche sur laquelle les couleurs des décors ressortaient bien ${ }^{92}$. N. I. Sokol'skij a remarqué que les sarcophages des périodes anciennes, jusqu'au I ${ }^{\mathrm{er}}$ s. av. J.-C., étaient polis et passés à l'huile et à la cire ${ }^{93}$. Sur les sarcophages plus récents, le blanchiment avait sans doute pour fonction de cacher une surface non polie. En même temps, cela résolvait le problème de la conservation du bois et donnait une couche de fond aux couleurs appliquées par-dessus.

Les éléments en stuc étaient également enduits de chaux, mais la nature des restes observés montre que cette couche était appliquée après la fixation des stucs sur les parois du sarcophage, puisqu'en effet, seules sont recouvertes les surfaces des parties saillantes. La couleur était appliquée selon le principe de la fresque, sur une surface blanche humide. Les fragments ornementaux en stuc se distinguent par la vigueur expressive de formes complexes et les contrastes de couleurs des facettes. Les grands acrotères, par exemple, montrent des restes de couleurs rose orangé et bleu clair.

A. P. Ivanova a établi une liste des caractéristiques des reliefs en stuc $^{94}$ :

- l'expressivité psychologique des visages frise souvent le grotesque et est en contradiction avec l'effet décoratif des figures;

- les colonnes forment des divisions qui rompent le lien entre les figures et leur effet d'ensemble, ce qui rappelle les sarcophages d'Asie Mineure;

- le mouvement des figures se déroule sur un seul plan, ce qui est en contradiction avec le modelé plastique;

92. N. K. Žižina, «Kompleks gipsovykh rel'efov iz zemljanogo sklepa nekropolja Nimfeja i voprosy rekonstukcii dekora bosporskikh derevjannykh sarkofagov rimskogo vremeni», p. 156 sq.

93. N. I. Sokol'skij, Derevoobrabatyvajuščce remeslo v antičnykh gosudarstvakh Severnogo Pričernomor' ja, p. 115.

94. A. P. Ivanova, «Khudožestvennye izdelija iz dereva i kosti», p. 424-427. 
- les masques de Méduse et les masques de théâtre présentent des traits physionomiques propres, différents de ceux du type classique, par une expressivité plus appuyée qui confine au grotesque ${ }^{95}$;

- de même que la peinture monumentale bosporane, les appliques de stuc se distinguent par leur polychromie aux couleurs vives ${ }^{96}$.

De l'examen de toutes les informations présentées ici sur le décor des sarcophages de bois, il est possible de tirer les conclusions suivantes:

- les appliques de stuc étaient étroitement liées à la forme du sarcophage et adaptées à celle-ci;

- elles se répartissent, selon la forme du sarcophage, sur plusieurs registres et frises;

- les reliefs de stuc ont pour cadre naturel les planches des angles et les planches horizontales du sarcophage, ainsi que les colonnes et colonnes engagées sur leurs parois;

- parmi les reliefs, certains sont à mettre à part pour leur signification particulière; ils avaient surtout une fonction apotropaïque et occupaient un emplacement central dans les parties principales de la composition (les représentations des Niobides, par exemple, ou les masques de Méduse);

- il y a également des représentations dont l'appartenance au «monde supérieur» de la composition d'ensemble est mise en évidence (les oiseaux, par exemple, ou les acrotères ajourés en hauteur);

- un nombre particulièrement important d'appliques est constitué par des éléments de décor végétal: rameaux, palmettes, rosettes, feuilles; dans l'ensemble, elles paraissent avoir généreusement recouvert les parois des sarcophages et y avoir été disposées librement;

- dans la tonalité des appliques et des fonds, les couleurs vives dominent, souvent associées pour faire contraste; les contours d'un noir éclatant autour des yeux, des mèches de cheveux, etc. jouent un rôle important. 
La plupart de ces principes trouvent des analogies dans la peinture funéraire bosporane de la même époque ( $\mathrm{I}^{\mathrm{er}}-\mathrm{II}{ }^{\mathrm{e}}$ s. apr. J.-C. ${ }^{97}$.

\section{Les analogies dans la peinture funéraire bosporane}

Les peintures murales des hypogées du Bosphore Cimmérien, conformément aux conventions en usage dans les chambres funéraires, présentent plusieurs registres et frises divisés par des représentations peintes de tablettes moulurées.

On trouve là également des figures typiques de la mythologie (Éros, Attis, la Gorgone Méduse), ainsi que de nombreux motifs paysagers et des éléments de "l'arbre de vie» sous la forme de rameaux et de rosettes.

Il existe aussi un sentiment analogue d'un monde éclatant et gorgé d'émotions, une simplicité et une expressivité du dessin qui l'emportent sur la narrativité et la précision du rendu. Ces particularités créent une atmosphère d'irréalité originelle.

A. P. Ivanova a dégagé une série de caractéristiques de la peinture bosporane des $\mathrm{I}^{\mathrm{er}}$ et $\mathrm{II}^{\mathrm{e}}$ siècles et les a mises en relation avec une influence de l'art sarmate ${ }^{98}$ :

- un style conventionnel et hiératique: dans les représentations de la figure humaine, la pose frontale, l'immobilité stricte et l'isolement statuaire sont prédominants;

- le réalisme ethnographique;

- une caractérisation simplifiée, mais profonde et pénétrante du visage humain;

- l'asymétrie du visage est un élément essentiel de son traitement;

- la composition de la peinture est plus ou moins soumise à des formes architecturales, mais dans tous les cas, elle interagit avec elles;

- la planéité du dessin des figures;

- une couleur pure et d'emploi limité à des surfaces restreintes, des contours aux lignes nettes;

- le principe de l'alternance des couleurs faisant contraste;

97. P.-A. Kreuz, "Bilder und Bildräume in den Nekropolen des Bosporanischen Reich im 1./2. Jh.", p. 185 sq.

98. A. P. Ivanova, "O nekotorykh osobennostjakh bosporskoj živopisi » et «Khudožestvennye izdelija iz dereva i kosti», p. 427. 


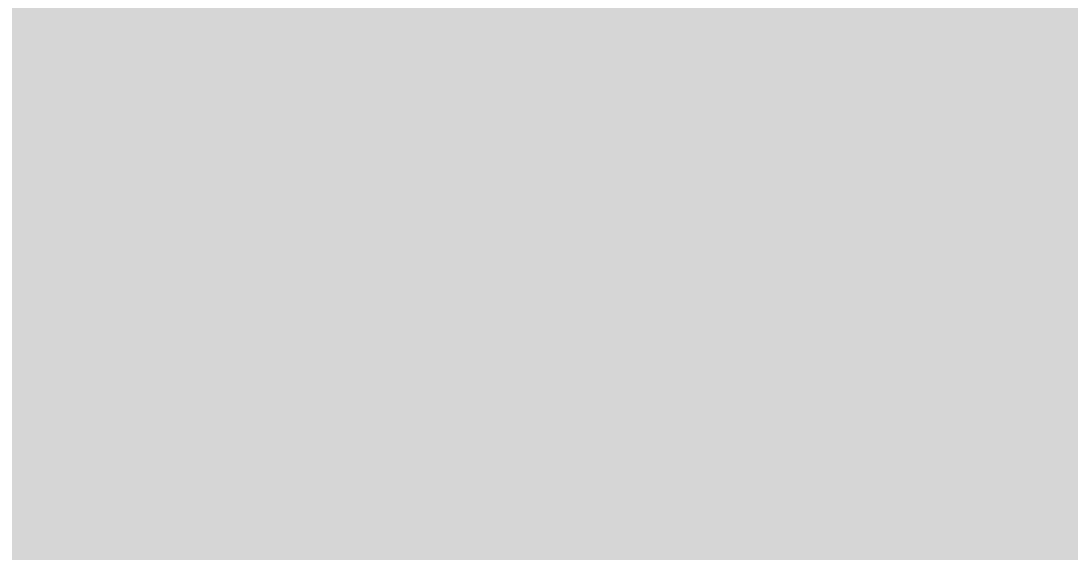

Fig. 7 - Presqu'île de Taman. Kourgane du mont Vasjurin, 1868. Peintures sur les parois du tombeau. Dessin de F. I. Gross. NA IIMK RAN, r. I, op. 1, d. 565, 1. 9. (C) Institut d'histoire de la culture matérielle, Académie des sciences de Russie, SaintPétersbourg, 2019.

- une différence conventionnelle dans la grandeur des personnages représentant des maîtres et des esclaves.

En se fondant sur l'étude des monuments funéraires, G. I. Sokolov distingue trois périodes dans l'évolution de la peinture bosporane: 1. période du style dit floral, avec des représentations de pétales de fleurs sur un fond de couleur ( $\mathrm{I}^{\mathrm{er}}$ s. apr. J.-C.) ; 2. période des compositions du style à incrustations imitant des revêtements de marbre polychromes (fin du ${ }^{\mathrm{er}}-\mathrm{II}^{\mathrm{e}}$ s. apr. J.-C.) ; 3. période d'épuisement de la tradition (III ${ }^{\mathrm{e}}$ $I^{e}$ s. apr. J.-C.) ${ }^{99}$. Il est intéressant d'observer que l'art grec et l'art romain ont aussi connu un style à incrustations, tandis que le Bosphore Cimmérien est seul à avoir un style floral. Les compositions les plus expressives sont celles où sont associés les styles floral et à incrustations, et ce sont précisément elles qui montrent le plus d'analogies avec le décor des sarcophages.

L'un des plus curieux parallèles que l'on puisse établir avec les décors de stuc des sarcophages est l'exemple du tombeau peint du premier kourgane du mont Vasjurin (fig. 7) ${ }^{100}$. Il fut mis au jour en 1868-1869

99. G. I. Sokolov, Iskusstvo Bosporskogo carstva, p. 415.

Ioo. M. Rostovtseff, La peinture décorative antique en Russie méridionale, p. 56-105, pl. XI.2, XII-XXV. 
et fit l'objet d'investigations complémentaires en 1907. La peinture de la chambre funéraire est structurée et imite une incrustation de marbre de couleur. La partie supérieure du mur présente un large champ rouge délimité en bas par une frise à kymation lesbique et en haut par une corniche peinte avec des gargouilles en mufle de lion, sur laquelle sont posés des oiseaux alternant avec de petits acrotères. Une telle reproduction d'une partie d'un temple ou d'un hérôon ${ }^{101}$ 's'inscrivait vraisemblablement dans un programme d'héroïsation du défunt inhumé là. Quant à la composition et à la symbolique, la corniche aux mufles de lion et aux acrotères rappelle le système décoratif des sarcophages. Les petits oiseaux attirent tout particulièrement l'attention. Avec leur tête rouge et leurs ailes bleu foncé, ils sont assis le long de la latte supérieure de la composition architecturale de la corniche, et c'est précisément ainsi qu'ont pu être disposés les oiseaux sur le sarcophage de la nécropole de Tyritakè dont nous avons proposé une reconstitution dessinée. Selon M. Rostovtseff, la construction de ce tombeau n'est en aucun cas postérieure à la deuxième moitié du III' s. av. J.-C. ${ }^{102}$.

Le tombeau double découvert en 1873 sur le mont Mithridate présente un autre genre de composition (fig. 8) ${ }^{103}$. Les murs et les voûtes sont entièrement recouverts de feuilles vertes et de pétales de roses parmi lesquels sont figurés des oiseaux et des femmes planant en tenant un voile. Dans la première chambre funéraire sont représentés des paons, un sanglier, un combat singulier entre deux cavaliers et la scène du retour de Korè, qui symbolise l'arrivée du printemps et le renouveau. L'ensemble de la composition associe des scènes héroïques et des scènes mythologiques dans un contexte général de renouveau de la nature. Un vent chaud associé aux pétales de fleurs, au gazouillement des oiseaux bigarrés et aux figures des jeunes filles fait souffler une atmosphère de printemps et de réveil. M. Rostovtseff datait ce tombeau de la fin du ${ }^{\text {er }}$ ou du II $s$. apr. J.-C. ${ }^{104}$. Il est important d'observer que les compositions «florales" deviennent alors très populaires, et que c'est à la même époque qu'elles se répandent aussi dans les reliefs de stuc décorant les sarcophages. Sur ces reliefs, la symbolique spécifique du décor trouve à s'exprimer

IOI. C'est aussi Rostovtseff qui a suggéré l'analogie avec un hérôon: ibid., p. 95.

I02. Ibid., p. 68 et 91.

I03. Ibid., p. 227-243, pl. LXIII-LXIV.1-3.

I04. Ibid., p. 307. 
Fig. 8 - Kertch. Hypogée «double» découvert en 1873. Peinture à la fresque sur le plafond de la première chambre funéraire. Fragment. Dessin de F. I. Gross. NA IIMK RAN, r. I, op. 1, d. 566, 1. 7. (C) Institut d'histoire de la culture matérielle, Académie des sciences de Russie, Saint-Pétersbourg, 2019.

Fig. 9 - Kertch. Hypogée «double» découvert en 1873. Peinture à la fresque sur le plafond de la deuxième chambre funéraire. Dessin de F. I. Gross. NA IIMK RAN, r. I, op. 1, d. 566, 1. 12. (C) Institut d'histoire de la culture matérielle, Académie des sciences de Russie, Saint-Pétersbourg, 2019. 


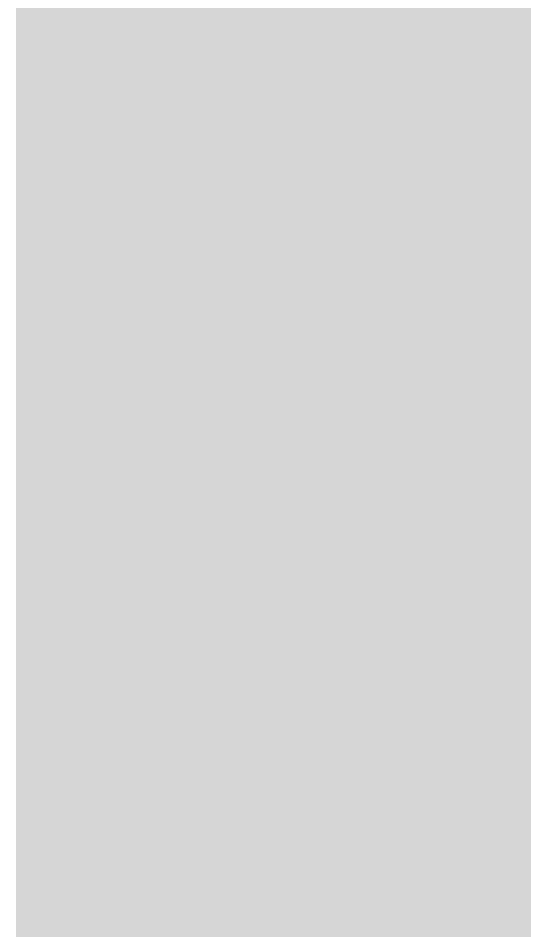

Fig. 10 - Kertch. Hypogée découvert en 1875. Peinture sur le mur du tombeau. Dessin de F. I. Gross. NA IIMK RAN, r. I, op. 1, d. 564, 1. 6. (C) Institut d'histoire de la culture matérielle, Académie des sciences de Russie, Saint-Pétersbourg, 2019. dans l'abondance des ornements végétaux, ainsi que nous l'avons déjà observé. Ces palmettes, ces rameaux, ces rosettes, ces boutons de lotus ne semblent pas avoir une place déterminée dans le système du décor des sarcophages. Cette liberté et ce foisonnement de petites feuilles et de pétales, dont les sarcophages-temples paraissent parsemés, suggèrent la même idée de régénération par un vent printanier.

La seconde chambre funéraire du tombeau double est de moindres dimensions et dépourvue de scènes figurées. Les murs et le couvrement présentent une surface unie. La peinture qui les recouvre montre des feuilles, des pétales de roses, des guirlandes et des oiseaux. Le centre de la voûte est occupé par un masque de Méduse de face, le front surmonté d'ailes, dans une bordure de guirlande (fig. 9). Ce masque est très semblable à ceux en stuc et il a une position centrale comme sur les sarcophages. C'est dans les murs de cette chambre funéraire qu'étaient aménagées les niches pour la disposition des corps; en d'autres termes, il s'agit de l'emplacement qui, par sa fonction rituelle, est le plus proche des sarcophages ${ }^{105}$.

Les peintures du tombeau découvert en 1875 sont d'un style mixte floral et à incrustations (fig. 10) ${ }^{106}$. Les éléments structurants sont ici d'épaisses colonnes ioniques. Entre les colonnes est disposé un décor

I05. Selon Rostovtseff, «le cercueil remplaçait la $\kappa \lambda$ ív $\eta$, mais la conception ionienne du défunt héroïsé s'est maintenue dans nos tables et dans nos bancs" (ibid., p. 95).

Io6. Ibid., p. 356-368, pl. LXXIII-LXXV. 
à incrustations, et au-dessus, la surface est couverte d'un décor floral. M. Rostovtseff datait ce tombeau de la première moitié du IIe siècle ${ }^{107}$.

Le tombeau de Sorakos, sur le mont Mithridate (Kertch), fut découvert en 1890 et étudié par Ju. A. Kulakovskij ${ }^{108}$. Il tire son nom de celui du défunt enterré là et cité sur une épitaphe. La peinture date de la fin du $\mathrm{II}^{\mathrm{e}}$ ou de la première moitié du III siècle. Toute la surface des murs audessus du soubassement, les piliers et la voûte étaient ornés de rameaux, de feuilles et de pétales de roses. Les scènes figurées sont ici également disparates et peu nombreuses. La composition du pilier occidental attire particulièrement l'attention avec l'épitaphe dans un cartouche et des Éros planant en tenant une guirlande.

Les Éros, planant ou chevauchant des dauphins ou des taureaux, sont aussi des figures très appréciées sur les décors de stuc des sarcophages. Leur présence au milieu de pétales de rose tombant des airs invite à se rappeler l'histoire de Psychè, l'âme humaine ranimée par Éros, personnification de l'amour. Dans l'art funéraire, les Éros deviennent de petits génies qui font souffler le vent dans les compositions florales.

\section{L'art du Bosphore Cimmérien et le style bosporan}

A. P. Ivanova tire une conclusion très importante sur l'originalité de l'art bosporan:

Les peintures funéraires de Panticapée des Irr-III $^{\mathrm{e}}$ siècles et les stèles funéraires de la même époque montrent qu'il s'était formé alors dans le Bosphore Cimmérien un style artistique tout à fait unique ${ }^{109}$.

Et d'ajouter:

On peut suivre des processus similaires - avec les variations connues dans toutes les régions barbares à la périphérie de l'Empire romain. Sans même parler d'Olbia et de Chersonèse, l'évolution artistique, en Thrace, en Phrygie, à Palmyre et en Afrique, fait voir une série de phénomènes analogues à ceux que l'on observe dans le milieu bosporan ${ }^{110}$.

I07. Ibid., p. 366 sq.

Io8. Ibid., p. 310-320, pl. LXV.4.

I09. A. P. Ivanova, «Čerty mestnogo stilja v derevjannoj rez’be Bospora rimskogo vremeni», p. 167.

IIo. Ibid., p. 192. 
E. A. Savostina, se fondant sur l'exemple de la sculpture monumentale, conclut à l'apparition d'un «nouveau phénomène artistique, chargé d'une énergie créatrice inaccessible à l'art idéalisant du classicisme grec ${ }^{111}$ ". Elle voit en outre dans le «style bosporan" une réponse à «l'impulsion» reçue au $\mathrm{VI}^{\mathrm{e}}$ s. av. J.-C. avec la colonisation du littoral nord du Pont-Euxin, et par conséquent une des branches de l'art grec. Le style bosporan, selon elle, a notamment pour particularités ${ }^{112}$ :

- la nature conventionnelle de la forme, sa planéité;

- la frontalité dans la construction des figures;

- les volumes marqués par une ligne de contour;

- la délimitation des éléments d'une même structure;

- l'effet décoratif obtenu par un rendu minutieux des détails, qui souligne leur symbolique;

- l'uniformisation;

- la complexité de l'expression, qui inclut des éléments de styles différents - archaïque, style sévère, classicisme - en mêlant un traitement archaïque de l'espace par couches distinctes et la position classique des figures, représentées de trois quarts selon un axe de rotation;

- le caractère fondamentalement hellénique du langage formel des monuments bosporans, qui s'exprime par l'intention appuyée d'adopter le point de vue de la statuaire;

- les traits hellénisants du modelé de la surface.

Les reliefs en stuc des sarcophages bosporans reflètent les particularités de l'évolution du style artistique régional. Celui-ci a pour trait déterminant d'appartenir à la grande tradition grecque. Parmi les premiers archéologues qui ont étudié les reliefs de stuc, la plupart ont remarqué leur lien avec l'art grec ${ }^{113}$. S. A. Žebeljov, par exemple, dans son étude sur les Niobides de Panticapée, a comparé les reliefs de Kertch

III. E. A. Savostina, "Grečeskaja periferija i osobennosti razvitija iskusstva na okraine èllinskogo mira", p. 84.

II2. E. A. Savostina, Ellada i Bospor, p. 305-310 et 344.

II3. L. I. Stephani, in Compte rendu de la Commission Impériale Archéologique pour l'année 1863, p. 166; V. V. Škorpil, in Izvestija Imperatorskoj Arkheologičeskoj Komissii, 1904, p. 164: «Les Niobides sont une œuvre d'époque romaine réalisée évidemment sous l'influence de modèles plus anciens." 
aux figures de Niobides en terre cuite découvertes en Grande-Grèce et démontré qu'ils remontent à des modèles du $\mathrm{V}^{\mathrm{e}}$ s. av. J.-C. ${ }^{114}$.

$\mathrm{Au} \mathrm{XIX}^{\mathrm{e}}$ siècle déjà, des auteurs avaient toutefois remarqué une autre particularité du style bosporan. On lit par exemple dans le Compte rendu de la Commission Impériale Archéologique pour l'année 1872:

L'intérieur de la chambre sépulcrale, découverte en 1872 , produit dès le premier coup d'œil l'effet de quelque chose d'oriental, et nullement grec, encore moins romain ${ }^{115}$.

Selon cet auteur, c'est la tradition même des hypogées qui est liée à l'Orient:

Toute l'Asie Mineure est remplie de telles sépultures; la Phrygie et la Lycie à l'Ouest et au Sud, la Galatie au centre, la Cappadoce et le Pont à l'Est et au Nord, offrent des nécropoles entières, construites selon ce système [...] Quant à nos tombes de Kertch, elles ont une physionomie qui nous reporte tout particulièrement en Asie Mineure ${ }^{116}$.

Dans sa thèse, N. K. Žižina affirme que les particularités stylistiques des reliefs en stuc se sont développées dans un processus d'interaction entre les éléments grecs et indigènes du royaume du Bosphore:

Surtout, cette association entre la tradition de l'art grec avec son rationalisme et la tradition barbare avec tout ce qu'elle a d'irrationnel a finalement donné naissance, sur le littoral nord de la mer Noire, à un style qui est considéré comme un exemple rare de fusion entre deux cultures, un style d'une étonnante capacité d'absorption, d'une grande brillance émotionnelle et d'une forte expressivité due à la nature des procédés et moyens artistiques utilisés ${ }^{117}$.

On doit toutefois à G. I. Sokolov une observation importante: à l'époque romaine, ce que Rostovtseff désignait du terme de "gréco-iranien" se complique considérablement du fait de la naissance d'un art gréco-

II4. S. A. Žebeljov, Pantikapejskie Niobidy.

II5. W. Stassoff, in Compte rendu de la Commission Impériale Archéologique pour l'année 1872 , p. 249.

II6. Ibid., p. 251 et 253.

I17. N. K. Žižina, Gipsovyj rel'efv pogrebal'nykh pamjatnikakh Evropejskogo Bospora pervykh vekov n. è., p. 101 et 139; sur la question de la synthèse des deux cultures, cf. p. 115-122. 
romain d'une part, et scytho-sarmate de l'autre, raison pour laquelle il est difficile, dans l'art bosporan des premiers siècles, de déterminer les sources d'inspiration de telle ou telle ouvre, et de mettre en évidence les causes de l'apparition de formes diverses ${ }^{118}$. Selon lui, il se manifeste dans l'art bosporan des tendances contradictoires, par exemple la juxtaposition, dans la peinture des caveaux funéraires, d'un style floral libre et chaotique, et, à l'opposé, d'un style à incrustations bien ordonné ${ }^{119}$.

Les premiers siècles de notre ère virent l'affermissement du pouvoir des souverains d'origine sarmate à la tête du royaume du Bosphore. A. P. Ivanova reconnaît également des traits de style barbare dans la peinture bosporane de cette époque ${ }^{120}$. Les auteures du catalogue du Louvre mettent elles aussi les brillantes polychromies des décors de sarcophages en stuc en rapport avec l'influence sarmate ${ }^{121}$.

Nous pouvons ainsi affirmer que les stucs des sarcophages font partie intégrante du "style bosporan" avec sa manière d'allier des traditions diverses sur un fond grec et de mêler des traits stylistiques de plusieurs époques, et avec sa brillante polychromie rehaussée par le caractère ornemental et l'expressivité.

Sur les monuments bosporans, et principalement les peintures des hypogées et les reliefs des sarcophages, on observe une série de particularités caractéristiques. L'absence de narration directe, par exemple, ou la réduction des thèmes héroïques. Il ne s'y trouve aucun récit complet, mais seulement des scènes séparées de combat singulier, de chasse ou de festin, des personnages et des animaux isolés. Les figures mythologiques apparaissent comme un élément, non pas d'une histoire, mais de l'univers créé, et comme une manifestation de la puissance de la nature.

Les reliefs de stuc sur les sarcophages réunissent en une combinaison intéressante les ordres de l'architecture des temples, avec les colonnes, et des éléments de l'arbre de vie, avec les rameaux et les oiseaux, et cela caractérise aussi la peinture des hypogées bosporans. Les sarcophages à relief de stuc associent une structure architecturale rigoureuse et son remplissage par des éléments isolés d'ornement végétal. Il s'agit au fond

II8. G. I. Sokolov, Iskusstvo Bosporskogo carstva, p. 350 sq.

II9. Ibid., p. 417 sq.

I20. A. P. Ivanova, "O nekotorykh osobennostjakh bosporskoj živopisi», p. 296.

I2I. P. Pinelli, A. Wąsowicz, Catalogue des bois et stucs grecs et romains provenant de Kertch, p. 26. 
d'un amalgame de deux principes opposés: d'un côté la structure ordonnée et logique de l'ensemble, et de l'autre la légèreté et la structure aléatoire d'une multitude éparse. Ces deux principes dessinent ensemble une carte complexe du monde où se trouvent à la fois les structures monumentales stables du culte des héros et la vitalité éclatante et polymorphe qui s'écoule à travers elles. L'un et l'autre évoquent l'éternité dans leurs deux hypostases, statique et dynamique. Dans l'art bosporan, ils se manifestent comme une unité.

6. Les sarcophages-temples. L'idée d'héroïsation du défunt, ses origines et son traitement dans l'art bosporan

L'idée essentielle du sarcophage-temple est liée à l'héroïsation du défunt. Les peintures des tombeaux bosporans montrent également une manière particulière de la traiter, qui associe l'hérö̈que "souvenir impérissable» et l'éternelle félicité du printemps. C'est un héritage des temps anciens qui virent l'apparition dans le monde grec des premiers héros vivants divinisés.

On trouve chez Platon des réflexions sur la «classe des philosophes»:

Ils passeront la plus grande partie de leur temps dans l'étude de la philosophie, mais quand leur tour viendra, ils accepteront de peiner aux tâches d'administration et de gouvernement par amour pour la cité, y voyant non pas une noble occupation, mais un devoir indispensable; et ainsi, après avoir formé sans cesse des hommes qui leur ressemblent, pour leur laisser la garde de l'État, ils iront habiter les îles des Bienheureux. La cité leur consacrera des monuments et des sacrifices publics, à titre de démons, si la Pythie le permet, sinon, à titre d'âmes bienheureuses et divines ${ }^{122}$.

Il décrit encore le rite funéraire convenant à ces personnes distinguées, et même la construction du tombeau:

La tombe sera construite en voûte souterraine, rectangulaire, faite de pierres de tufeau absorbantes et les moins sujettes que possible à

I22. Platon, République, 540 (trad. Robert Baccou). 
l'usure, avec des lits de pierre rangés parallèlement. On y déposera le corps du bienheureux ${ }^{123}$.

La tradition de l'héroïsation du défunt intégrée au programme des constructions et des rites funéraires a trouvé une expression éclatante dans les monuments d'Asie Mineure - où elle s'ajoutait aux particularités des rites locaux -, tels les hérôa et les tombeaux lyciens. Leur typologie même est un reflet de la recherche dans le domaine du mausolée idéal à ciel ouvert: le tombeau du lion et le tombeau des Harpyes, l'un et l'autre élevés sur un pilier, et les constructions d'aspect similaire sur l'acropole de Xanthos, tous de la fin de l'époque archaïque, sont interprétées comme des hérôa. Enfin, le tombeau de Merehi et le tombeau de Payava (Lycie, Xanthos, v. 370-350) figurent plus directement encore les sarcophages-temples.

Les plus célèbres constructions de ce milieu sont le monument des Néréides à Xanthos (Lycie, v. 390-380) (fig. 11) et le mausolée d'Halicarnasse (Carie, v. 350). Ils se distinguent par une composition complexe à plusieurs registres qui réunissent un soubassement élevé, un ordre d'architecture, des scènes sculptées et des reliefs. En eux se fondent les traditions de l'Anatolie et du monde grec oriental. Les monuments funéraires, et en particulier le célèbre mausolée d'Halicarnasse, eurent une influence sur le développement des tombeaux macédoniens de l'époque de Philippe II ${ }^{124}$. Le «tombeau de Philippe II» allait devenir à son tour un modèle souvent imité (tombeau II, Vergina, v. 336) ${ }^{125}$.

Il est intéressant d'observer que pour la crémation, qui était alors le rite prédominant, on utilisait une "maison» (oikos) de bois, dont la tombe I (tombe de la reine Eurydice, Vergina, v. 344-343) a livré des vestiges. C'est vraisemblablement un bûcher funéraire semblable que l'on construisit pour Philippe II, sur lequel il fut accompagné de sa plus jeune épouse, ainsi que des chevaux et des chiens qu'il aimait ${ }^{126}$. Ce rite lié à la divinisation et à la purification du roi rappelle les traditions funéraires

I23. Platon, Les Lois, 947d (trad. Auguste Diès).

I24. R. A. Tomlinson, "The architectural context of the Macedonian vaulted tombs", p. 307; T. P. Kisbali, «Understanding parallels between Macedonian and Carian funerary architecture in the 4th century BC».

I25. A. Kottaridi, "Burial customs and beliefs in the royal necropolis of Aegae», p. 145 .

I26. Ibid., p. 145 sq., fig. 167. 
Fig. 11 - Monument des Néréides, tombeau d'Erbinna, gouverneur de Xanthos, vers 390-380. British Museum, Londres. Photographie d'O. Ju. Samar.

de l'épopée homérique et le bûcher d'Héraclès ${ }^{127}$. C'est dans les tombeaux macédoniens précisément que naît le cycle de représentations de Déméter et de l'enlèvement de Perséphone. Quant à la maison de bois, elle rappelle les sarcophages du même matériau en forme de temple, répandus en Asie Mineure et dans le Bosphore.

Dans les tombeaux macédoniens du $\mathrm{IV}^{\mathrm{e}} \mathrm{s}$. av. J.-C., nous trouvons aussi le modèle architectural du portail, des cycles de peintures murales 
et de nombreux objets rituels signifiants (urnes, lits funéraires, trônes). L'agencement architectural attire l'attention par la préférence pour les ordres dorique et ionique, parfois réunis, par le respect de la structure et des proportions des ordres, et par la tonalité expressive que leur donnent des couleurs contrastées. Les angles peuvent être marqués par des pilastres (tombe du Jugement, Lefkadia, Náoussa [Mieza], fin du IVe-début du III ${ }^{\mathrm{e}}$ siècle) ou par des colonnes (tombe des Palmettes, Lefkadia, Náoussa [Mieza], III e siècle). Les parties comme les entrecolonnements, l'architrave, la frise et le fronton montrent des compositions picturales à thèmes héroïques ou figures de divinités et de héros. Les artisans combinent les éléments plastiques et sculpturaux. On remarque que les palmettes peuvent être aussi bien sculptées (tombe des Palmettes), que peintes sur la dalle (tombe de Hagios Athanasios). Un système correspondant de symboles se forme ici. La façade du tombeau de Hagios Athanasios, par exemple, montre un écu circulaire avec un masque de Méduse, prototype des appliques à gorgonéion réalisées plus tard en stuc. C'est vraisemblablement de là aussi que provient la couleur bleu clair traditionnellement appliquée sur les acrotères (tombe des Palmettes, tombe de Hagios Athanasios) ${ }^{128}$.

L'art bosporan, sous l'influence des monuments grecs, donne alors naissance à sa variante propre de monument à scènes peintes, dont le type le plus illustre est une stèle funéraire à représentation de guerrier dans la collection du Musée-réserve d'histoire culturelle de la Crimée orientale ${ }^{129}$. Il est important de noter que ce monument associe des éléments graphiques, comme le fronton, et des éléments plastiques, comme les saillies-acrotères.

Les procédés utilisés dans les grands monuments furent également adaptés pour les sarcophages de marbre de Sidon (Phénicie, 430-355), qui associent une forme de temple et une série de reliefs à thèmes hérö̈ques. Le sarcophage d'Alexandre montre un emploi systématique des ordres architecturaux, qui constituent le cadre des compositions en relief. Parmi celles-ci, on trouve des palmettes et des masques de boucs au bord du toit, des masques de Méduse et des oiseaux sur le faîte, un acrotère en hauteur avec des figures de sphinx sur le fronton. Le nouveau

I28. Voir en dernier lieu H. Brecoulaki, La peinture funéraire de Macédoine.

I29. VKIKMZ, inv. KL-1297; A. A. Zavojikin (otv. red.), Pantikapej i Fanagorija, no 351, p. 391 sq. 
Fig. 12 - Sarcophage des Pleureuses de la nécropole de Sidon, Lycie, 430-355. Musée d'archéologie, Istanbul. Photographie de N. A. Nalimova.

type de sarcophages bosporans en bois sculpté à colonnes, comme celui du kourgane de la batterie de Pavlovsk, près de Kertch, date du IVe s. av. J.-C. et témoigne de l'influence des sarcophages de Sidon ${ }^{130}$. De nombreux auteurs suggèrent un lien génétique entre les sarcophages du Bosphore Cimmérien et ceux de Sidon. La ressemblance entre les sarcophages bosporans aux Niobides et le sarcophage des Pleureuses (fig. 12) est particulièrement significative ${ }^{131}$. La composition à figures inscrites dans une colonnade était assez largement répandue; c'est celle qui est proposée dans la reconstitution de l'autel du temple de Priène ${ }^{132}$.

Les sarcophages d'Asie Mineure connurent ensuite une autre phase brillante d'évolution du I ${ }^{\mathrm{er}}$ au III ${ }^{\mathrm{e}}$ s. apr. J.-C. Il existait plusieurs centres

130. Compte rendu de la Commission Impériale Archéologique pour l'année 1859, p. 29 sq.

I3I. N. I. Sokol'skij, Antičnye derevjannye sarkofagi Severnogo Pričernomor'ja, p. 37 sq.; P. Pinelli, A. Wąsowicz, Catalogue des bois et stucs grecs et romains provenant de Kertch, p. 26 sq. et 29; P. Pinelli, "À propos d'un décor de sarcophage provenant de Kertch", p. 275 sq.; N. K. Žižina, Gipsovyj rel'ef v pogrebal'nykh pamjatnikakh Evropejskogo Bospora pervykh vekov n. è., p. 94-96.

132. I. Jenkins, Greek architecture and its sculpture in the British Museum, p. 246 sq. 
Fig. 13 - Sarcophage à guirlandes. Dokiméion, vers 150-180. Walters Art Museum, Baltimore. Photographie d'O. Ju. Samar.

importants de production des sarcophages de marbre. Pour le marché local, ils étaient réalisés à Aphrodisias (Carie) et à Éphèse, tandis que les ateliers de Dokiméion (Phrygie) et de Proconnèse (île de Marmara) fournissaient le marché plus lointain ${ }^{133}$. Les centaines d'exemplaires qui se sont conservés jusqu'à nos jours témoignent des immenses quantités produites.

Dokiméion, un des principaux centres de production, fournissait abondamment non seulement l'Asie Mineure, mais aussi l'Italie, la Grèce, la Syrie, la Palestine, Rhodes et la Crète (fig. 13). Ces sarcophages reprennent la forme du «temple» avec des détails architecturaux: toit en bâtière, acrotères, antéfixes en forme de mufle de lion ou de masque de théâtre. Le type du temple était très apprécié dans l'art des sarcophages d'Asie Mineure, parce que ceux-ci étaient traditionnellement conçus comme des mausolées; les sarcophages d'Aphrodisias, par exemple, étaient souvent exposés à ciel ouvert comme les hérôa ou les

I33. E. Öğüş, "Columnar sarcophagi from Aphrodisias», p. 113 sq. 
tombeaux d'autrefois ${ }^{134}$. Avec le temps, les couvercles des sarcophages d'Asie Mineure perdirent leur forme de toit pour représenter désormais un lit funéraire avec le défunt.

Les parois de tels sarcophages se composent d'une juxtaposition d'éléments décoratifs que séparent des colonnes, des arcades ou des guirlandes suspendues. À l'intérieur des champs ainsi définis sont disposés des personnages, des masques de Gorgone, des masques de théâtre, etc. ${ }^{135}$. Comme il est de règle, il s'agit de figures mythologiques et, à la différence de ce que montrent les sarcophages romains, les portraits de défunt sont rares ici.

Les créations des ateliers d'Asie Mineure furent vraisemblablement le point de départ des compositions des sarcophages bosporans et des épitaphes romaines, et cela d'autant plus qu'au $\mathrm{II}^{\mathrm{e}} \mathrm{s}$. apr. J.-C., les marbres de Proconnèse atteignirent le Bosphore Cimmérien ${ }^{136}$. L'idée fondamentale du sarcophage-temple et de ses reliefs a cependant une histoire plus ancienne. Et celle-ci ne débute pas en Grèce, mais en Asie Mineure. Malgré le développement formel que le classicisme tardif lui avait donné par l'emploi des ordres architecturaux, cette idée conservait en elle une certaine âcreté tout orientale qui plaisait aux Bosporans.

Nous pouvons donc constater que les sarcophages bosporans à reliefs de stuc réalisés aux I ${ }^{\mathrm{er}}$-II $\mathrm{e}$ s. apr. J.-C. poursuivent la tradition de l'héroïsation des défunts et s'assimilent à des hérôa. Ayant traversé plusieurs interprétations et adaptations, cette tradition subsista dans l'art bosporan et y trouva une nouvelle forme de narrativité, vivante, pleine d'émotion et libre.

\author{
Ol'ga Jur'evna Samar \\ Musée des Beaux-Arts Pouchkine, Moscou \\ Traduction du russe de Laurent Auberson
}

I34. E. Öğüş, Columnar sarcophagi from Aphrodisias, p. 1, 10 sq.

I35. A. Topbaş, «Un sarcophage d'Apamée de Phrygie».

I36. G. I. Sokolov, Iskusstvo Bosporskogo carstva, p. 353. 


\section{BIBLIOGRAPHIE}

$<$ http://bosporuscrypt.ru>

Akimova, Ljudmila Ivanovna, Tuguščeva, Ol'ga Vilenovna (otv. red.), Šedevry antičnogo iskusstva. Iz sobranija GMII A. S. Puškina [Chefs-d'euvre de l'art antique. La collection du Musée Pouchkine des beaux-arts], Moskva, Gosudarstvennyj Muzej izobrazitel'nykh iskusstv im. A. S. Puškina, 2011.

Antiquités du Bosphore Cimmérien conservées au Musée Impérial de l'Ermitage. Ouvrage publié par ordre de sa Majesté l'Empereur, Saint-Pétersbourg, imprimerie de l'Académie Impériale des Sciences, 1854.

Bejlin, Denis Vladislavovič, Rukovišnikova, Irina Viktorovna, Fedoseev, Nikolaj Fjodorovič, "Èlitnyj pogrebal'nyj pamjatnik Bosporskogo carstva kurgan "Gospital'nyj" (Po materialam novejšikh polevykh issledovanij v Vostočnom Krymu) » ["Le kourgane "Gospital'nyj", monument funéraire de l'élite du royaume du Bosphore (d'après les dernières recherches sur le terrain)», in Bosporskij fenomen. Obščee i osobennoe v istoriko-kul'turnom prostranstve Antičnogo mira [Le phénomène bosporan. Points communs et particularités de l'espace historico-culturel du monde antique], otv. red. Vadim Jur'evič Zuev, Vladimir Andreevič Khržanovskij, Sankt-Peterburg, Sankt-Peterburgskij Gosudarstvennyj Universitet promyšlennykh tekhnologij i dizajna, 2018, p. 175-180 (Materialy meždunarodnoj naučnoj konferencii, 1).

Berzina, Svetlana Jakovlevna, "Proizvodstvo gipsovykh izdelij na Bospore" [ "La production de stucs dans le Bosphore Cimmérien"], in Arkheologija i istorija Bospora [Archéologie et histoire du Bosphore Cimmérien], II, otv. red. L. M. Slavin, Simferopol', Gosudarstvennyj Kerčenskij istorikoarkheologičeskij muzej im. A. S. Puškina, 1962, p. 237-255.

Blavatskij, Vladimir Dmitrievič, "Raskopki nekropolja Tiritaki v 1933 g.» ["Les fouilles de la nécropole de Tyritakè en 1933 », in Arkheologičeskie pamjatniki Bospora i Khersonesa, [Monuments 
archéologiques du Bosphore et de Chersonèse], otv. red. Sergej Aleksandrovič Žebeljov et Viktor Francevič Gajdukevič, Moskva/ Leningrad, Izdatel'stvo Akademii nauk SSSR, 1941, p. 61-74 (Materialy i issledovanija po arkheologii SSSR, 4).

Brecoulaki, Hariclia, La peinture funéraire de Macédoine. Emplois et fonctions de la couleur (IV ${ }^{e} I I^{e}$ av. J.-C.), Athènes, de Boccard, 2006.

Compte rendu de la Commission Impériale Archéologique I Otčjot Imperatorskoj Arkheologičeskoj Komissii, pour l’année 1859 (1862); pour l'année 1863 (1864); pour l'année 1872 (1875); pour l'année 1875 (1878); pour l'année 1890 (1893); pour l'année 1891 (1893). GajDukevič, Viktor Francevič, "Istorija antičnykh gorodov Severnogo Pričernomor’ja (kratkij očerk)» ["Histoire des cités antiques du littoral nord de la mer Noire (brève esquisse) »], in Antičnye goroda Severnogo Pričernomor' ja. Očerki istorii i kul'tury [Les cités antiques du littoral nord de la mer Noire. Essais d'histoire culturelle], I, Moskva/Leningrad, Izdatel'stvo Akademii Nauk, 1955, p. 23-147.

GraČ, Nonna Leonidovna, "Raskopki nekropolja Nimfeja» ["Fouilles de la nécropole de Nymphée»], in Arkheologičeskie otkrytija 1974 g. [Découvertes archéologiques de l'année 1974], Moskva, Nauka, 1975, p. 270-271.

—, «Raskopki nekropolja Nimfeja v 1973-1974 gg. " [ Fouilles de la nécropole de Nymphée en 1973-1974»], in Novye otkrytija sovetskikh arkheologov. Tezisy dokladov [Nouvelles découvertes des archéologues soviétiques. Thèses des rapports], Kiev, 1975, p. 59-60.

—, "Raskopki nekropolja Nimfeja» ["Fouilles de la nécropole de Nymphée»], in Arkheologičeskie otkrytija 1977 g. [Découvertes archéologiques de l'année 1977], Moskva, Nauka, 1978, p. 314-315. —, Nekropol' Nimfeja, Sankt-Peterburg, Nauka, 1999.

ILlARIošKınA, Elena Nikolaevna, «Bogi i geroi grečeskikh mifov v bosporskoj koroplastike» [ Dieux et héros des mythes grecs dans la coroplastie bosporane»], Bosporskie issledovanija, 1 (2001), p. 213-218.

Ivanova, Anna Pavlovna, «Čerty mestnogo stilja v derevjannoj rez’be Bospora rimskogo vremeni» " «es traits stylistiques régionaux dans la sculpture sur bois du Bosphore à l'époque romaine»], in Trudy Otdela antičnogo mira Gosudarstvennogo Ërmitaža [Travaux 
du département des antiquités de l'Ermitage], I, Leningrad, Gosudarstvennyj Ėrmitaž, 1945, p. 167-197.

—, Iskusstvo antičnykh gorodov Severnogo Pričernomorj' ja [L'art des cités antiques du littoral nord de la mer Noire], Leningrad, Izdatel'stvo Leningradskogo Gosudarstvennogo Ordena Lenina Universiteta im. A. A. Ždanova, 1953.

—, «O nekotorykh osobennostjakh bosporskoj živopisi» [«Sur quelques particularités de la peinture bosporane»], in Antičnye goroda Severnogo Pričernomor'ja. Očerki istorii i kul'tury [Les cités antiques du littoral nord de la mer Noire. Essais d'histoire culturelle], I, Moskva/Leningrad, Izdatel'stvo Akademii nauk SSSR, 1955, p. 286-296.

—, «Khudožestvennye izdelija iz dereva i kosti» [«Objets d'art en bois et en os"], in Antičnye goroda Severnogo Pričernomor' ja. Očerki istorii $i$ kul'tury [Les cités antiques du littoral nord de la mer Noire. Essais d'histoire culturelle], I, Moskva/Leningrad, Izdatel'stvo Akademii nauk SSSR, 1955, p. 406-436.

Izvestija Imperatorskoj Arkheologičeskoj Komissii [Bulletin de la Commission impériale archéologique], 1903; 1904; 1913.

Jenkins, Ian, Greek architecture and its sculpture in the British Museum, Cambridge Mass., Harvard University Press, 2006.

Jijına, Nadia, "Nymphaion Necropolis in Bosporos", in Nécropoles et pouvoir. Idéologies, pratiques et interprétations. Actes du colloque Théories de la nécropole antique, Lyon 1995, éd. par Sophie Marchegay et al., Lyon/Athènes, Maison de l'Orient/École française d'Athènes, 1998, p. 199-216 (Travaux de la Maison de l'Orient méditerranéen, 27).

Kisbali, Tamás Péter, «Understanding parallels between Macedonian and Carian funerary architecture in the 4th century BC», in Makedonija-Rim-Vizantija: iskusstvo Severnoj Grecii ot antičnosti do srednikh vekov, otv. red. N. A. Nalimova, T. P. Kišbali, A. V. Zakharova, Moskva, Dobrosvet, 2018, p. 36-53.

Kivokurcev, Nikolaj Petrovič, «Bosporskaja gipsovaja statuètka Èrota» ["Une statuette d'Éros en stuc du Bosphore Cimmérien"], Sovetskaja arkheologija, VII (1941), p. 280-283.

Koвүlina, Marija Mikhajlovna, "Raskopki nekropolja Tiritaki v 1934 g.» " "Fouilles de la nécropole de Tyritakè en 1934 », in Arkheologičeskie pamjatniki Bospora i Khersonesa, [Monuments 
archéologiques du Bosphore et de Chersonèse], otv. red. Sergej Aleksandrovič Žebeljov, Viktor Francevič Gajdukevič, Moskva/ Leningrad, Izdatel'stvo Akademii nauk SSSR, 1941, p. 75-84 (Materialy i issledovanija po arkheologii SSSR, 4).

Kononov, Vasilij Nikolaevič, "K voprosu o tekhnike bosporskoj živopisi» " "La question de la technique de la peinture bosporane»], in Arkheologija i istorija Bospora [Archéologie et histoire du Bosphore Cimmérien], II, Simferopol', Gosudarstvennyj Kerčenskij istoriko-arkheologičeskij muzej im. A. S. Puškina, 1962, p. 279-280.

Kottaridi, Angeliki, "Burial customs and beliefs in the royal necropolis of Aegae", in Heracles to Alexander the Great. Treasures from the Royal Capital of Macedon, a Hellenic Kingdom in the Age of Democracy, Oxford, Ashmolean Museum, 2011, p. 131-152.

Kreuz, Patric-Alexander, "Bilder und Bildräume in den Nekropolen des Bosporanischen Reich im 1./2. Jh.: Grabreliefs, Grabmalerei, Sarkophage», in Bilder und Räume. Antike Sarkophage im Kontext. Internationale Tagung, 11.-12. August 2011 in der Abteilung Rom des Deutschen Archäologischen Instituts, hrsg. von Ortwin Dally, Johanna Fabricius, Henner von Hesberg, Wiesbaden, Reichert Verlag, 2018, p. 173-194.

Mirovoe nasledie Evropejskogo Bospora. Kollekcii Vostočno-Krymskogo istoriko-kul'turnogo muzeja-zapovednika [Le patrimoine mondial du Bosphore Cimmérien. Les collections du Musée-réserve d'histoire culturelle de la Crimée orientale], catalogue, Kertch, VostočnoKrymskij istoriko-kul'turnyj muzej zapovednik, 2016.

ÖĞüş, Esen, «Columnar sarcophagi from Aphrodisias: Elite emulation in the Greek East», American Journal of Archaeology, 118 (2014), p. 113-136.

—, Columnar sarcophagi from Aphrodisias, Wiesbaden, Reichert, 2018 (Aphrodisias, IX).

Pinelli, Paule, "À propos d'un décor de sarcophage provenant de Kertch", La Revue du Louvre et des Musées de France, 4 (1987), p. 273-277.

Pinelli, Paule, WĄsowicz, Aleksandra, Catalogue des bois et stucs grecs et romains provenant de Kertch, Paris, Éditions de la Réunion des musées nationaux, 1986. 
Rostovcev, Mikhail Ivanovič, Skifija i Bospor: Kritičeskoe obozrenie pamjatnikov literatury i arkheologii [La Scythie et le Bosphore: revue critique des monuments de la littérature et de l'archéologie], Leningrad, Izdatel'stvo Rossijskoj Akademii istorii material'noj kultury, 1925. Rostovtseff, Mikhaïl, La peinture décorative antique en Russie méridionale (Saint-Pétersbourg, 1913-1914), dir. Alix Barbet, trad. Arlette Fraysse et Andrea Rychtecky, 2 vols, Paris, de Boccard, 2004 (Mémoires de l'Académie des inscriptions et belles-lettres, XXVIII).

Savostina, Elena Anatol'evna, "Grečeskaja periferija i osobennosti razvitija iskusstva na okraine èllinskogo mira» [ "La périphérie grecque et les particularités de l'évolution artistique aux confins du monde hellénique»], in Bosporskij fenomen. Isskustvo na periferii Antičnogo mira. Materialy meždunarodnoj naučnoj konferencii [Le phénomène bosporan. Les arts à la périphérie du monde antique. Communications du congrès scientifique international], otv. red. M. Ju. Vakhtina, O. Ju. Sokolova, E. V. Gricik, V. Ju. Zuev, S. V. Kašaev, V. A. Kršanovskij, Sankt-Peterburg, Nestor-Istorija, 2009, p. 81-84.

—, Ellada i Bospor. Grečeskaja skul'ptura na Severnom Ponte [L'Hellade et le Bosphore. La sculpture grecque sur le littoral nord du PontEuxin], Simferopol'/Kertch, Centr arkheologičeskikh issledovanii Blagotvoritel'nogo fonda "Demetra», 2012 (Bosporos Studies, Supplementum, 8).

Sokolov, Gleb Ivanovič, "O portretnoj golovke iz gipsa v sobranii Gosudarstvennogo Ėrmitaža» ["À propos d'un portrait en stuc de la collection de l'Ermitage»], Soobščenija Gosudarstvennogo ordena Lenina Ėrmitaža, 28 (1967), p. 38-40.

—, Iskusstvo Bosporskogo carstva [L'art du royaume du Bosphore], Moskva, Izdatel'stvo MËI, 1999.

Sokol'skij, Nikolaj Ivanovič, Antičnye derevjannye sarkofagi Severnogo Pričernomor'ja [Les sarcophages de bois antiques du littoral nord de la mer Noire], Moskva, Nauka, 1969 (Svod arkheologičeskikh istočnikov [Corpus des sources archéologiques], 1-17).

—, Derevoobrabatyvajuščee remeslo v antičnykh gosudarstvakh Severnogo Pričernomor' ja [L'artisanat du bois dans les États antiques du littoral nord de la mer Noire], Moskva, Izdatel'stvo Akademii nauk SSSR, 1971 (Materialy i issledovanija po arkheologii SSSR, 178). 
Šul'c, Pavel Nikolaevič, Mavzolej Neapolja Skifskogo [Le mausolée de Néapolis des Scythes], Moskva, Iskusstvo, 1953.

Tomlinson, Richard A., «The architectural context of the Macedonian vaulted tombs", Annual of the British School at Athens, 82 (1987), p. 305-312.

Topвaş, Ahmet, «Un sarcophage d'Apamée de Phrygie», Revue archéologique, 2 (1987), p. 361-374.

VINOKURov, Nikolaj Igorevič, "Khudožestvenno-dekorativnye èlementy ukrašenij bosporskikh sarkofagov (po materialam nekropolja gorodišča Artezian)" ["Les éléments artistiques des décors des sarcophages bosporans (d'après le matériau des fouilles de la nécropole d'Artezian) »], in Bosporskij fenomen. Isskustvo na periferii Antičnogo mira. Materialy meždunarodnoj naučnoj konferencii [Le phénomène bosporan. Les arts à la périphérie du monde antique. Communications du congrès scientifique international], otv. red. M. Ju. Vakhtina, O. Ju. Sokolova, E. V. Gricik, V. Ju. Zuev, S. V. Kašaev, V. A. Kršanovskij, Sankt-Peterburg, Nestor-Istorija, 2009, p. 171-179.

Vorošilova, Ol'ga Mikhajlovna, «Rel'efnye ukrašenija derevjannykh sarkofagov Fanagorii» [«Les ornements en relief des sarcophages de bois de Phanagorie»], Rossijskaja Arkheologija, 2 (2012), p. 81-88.

Zavojikin, Aleksej Andreevič (otv. red.), Pantikapej i Fanagorija. Dve stolicy Bosporskogo carstva [Panticapée et Phanagorie. Les deux capitales du royaume du Bosphore], Moskva, Gosudarstvennyj Muzej izobrazitel'nykh iskusstv im A. S. Puškina, 2017.

Žebeljov, Sergej Aleksandrovič, Pantikapejskie Niobidy [Les Niobides de Panticapée], Sankt-Peterburg, 1901 (Drevnosti Južnoj Rossii. Materialy po arkheologii Rossii, izdavaemye Imperatorskoj arkheologičeskoj komissiej [Antiquités de la Russie méridionale. Matériaux archéologiques publiés par la Commission impériale archéologique], 24).

ŽIžInA, Nadežda Konstantinovna, "Izdelija iz dereva i gipsovye ukrašenija derevjannykh sarkofagov iz Pantikapeja v sobranii Luvra» ["Objets de bois et décors en stuc de sarcophages de bois de Panticapée dans la collection du Louvre»], Vestnik drevnej istorii, 1 (1990), p. 228-235. 
—, «Kompleks gipsovykh rel'efov iz zemljanogo sklepa nekropolja Nimfeja i voprosy rekonstukcii dekora bosporskikh derevjannykh sarkofagov rimskogo vremeni " " Un ensemble de reliefs en stuc provenant d'un hypogée en terre de la nécropole de Nymphée et la question de la reconstitution du décor des sarcophages bosporans en bois d'époque romaine»], in Trudy Gosudarstvennogo Ėrmitaža [Travaux de l'Ermitage], XXVIII, Sankt-Peterburg, Gosudarstvennyj Èrmitaž, 1997, p. 149-166.

—, «Četyre gipsovye applikacii I-II vv. iz raskopok Nimfeja vo sobranii Ėrmitaža» " Quatre appliques de stuc des I $^{\text {r }}$-II ${ }^{\mathrm{e}}$ siècles provenant des fouilles de Nymphée dans la collection de l'Ermitage", Soobščnija Gosudarstvennogo Ėmitaža, 63 (2005), p. 77-82.

—, Gipsovyj rel'ef v pogrebal'nykh pamjatnikakh Evropejskogo Bospora pervykh vekov n. è. (po materialam kollekcii Gosudarstvennogo Ermitaža) [Les reliefs en stuc dans les monuments funéraires des premiers siècles de notre ère dans le Bosphore Cimmérien (d'après les objets de la collection de l'Ermitage)], thèse, Sankt-Peterburg, 2007.

—, "Gipsovye tragičeskie maski kak èlement dekora bosporskikh derevjannykh sarkofagov I-II vekov (po materialam kollekcii Gosudarstvennogo Ėrmitaža)» [Les masques tragiques comme élément de décor des sarcophages bosporans en bois des $\mathrm{I}^{\mathrm{er}}$ et II ${ }^{\mathrm{e}}$ siècles (d'après les objets de la collection de l'Ermitage) »], in Maski: ot mifa k karnavalu [Masques: du mythe au carnaval], otv. red. Elena Anatol'evna Savostina, Tula, Vlasta, 2008, p. 90-104 (Vipperovskie čtenija, 38).

Žuravljov, Denis Valer'evič, Lomtadze, Georgij Al'bertovič, «Pogrebenie s derevjannym sarkofagom iz nekropolja Pantikapeja (raskopki Ju. A. Kulakovskogo v 1890 g.) » [«Une sépulture à sarcophage de bois dans la nécropole de Panticapée (fouilles de Ju. A. Kulakovskij en 1890)»], in Pogrebal'naja kul'tura Bosporskogo carstva. Materialy kruglogo stola, posvjaščennogo 100-letiju so dnja roždenija Mikhaila Moiseeviča Kublanova (19141998) [La culture funéraire du royaume du Bosphore. Pré-actes du symposium organisé à l'occasion du centenaire de la naissance de Mikhail Moiseevič Kublanov (1914-1998)], otv. red. Vadim Jur'evič Zuev, Vladimir Andreevič Khržanovskij, Sankt-Peterburg, Nestor-Istorija, 2014, p. 32-40. 